\title{
Evidence in hydrography and density fine structure for enhanced vertical mixing over the Mid-Atlantic Ridge in the western Atlantic
}

\author{
C. Mauritzen, ${ }^{1}$ K. L. Polzin, M. S. McCartney, R. C. Millard, and D. E. West-Mack \\ Physical Oceanography Department, Woods Hole Oceanographic Institution, Woods Hole, Massachusetts, USA
}

Received 24 August 2001; revised 22 February 2002; accepted 25 March 2002; published 15 October 2002.

[1] Anomalous conditions exist in the salinity, oxygen, and nutrient fields over the western flank of the Northern Hemisphere Mid-Atlantic Ridge. We examine possible advective sources for this anomaly, but determine that vertical mixing is the most likely cause. We proceed to use knowledge gained from the Brazil Basin Tracer Release Experiment in the South Atlantic (where microstructure and fine structure were obtained to explore the intensity, spatial distribution, and mechanisms of mixing in the deep ocean) to interpret density fine structure from common conductivity-temperature-depth data in the North Atlantic. These data support the hypothesis that the anomalous hydrographic conditions are associated with enhanced levels of vertical mixing. The inferred levels of vertical diffusivity over the Northern Hemisphere Mid-Atlantic Ridge are as high as in the South Atlantic: $1-10 \times 10^{-4} \mathrm{~m}^{2} / \mathrm{s}$. INDEX TERMS: 4532 Oceanography: Physical: General circulation; 4536 Oceanography: Physical: Hydrography; 4568 Oceanography: Physical: Turbulence, diffusion, and mixing processes; KEYWORDS: diapycnal mixing, fine structure, recirculation, Mid-Atlantic Ridge (MAR), hydrography, silicate

Citation: Mauritzen, C., K. L. Polzin, M. S. McCartney, R. C. Millard, and D. E. West-Mack, Evidence in hydrography and density fine structure for enhanced vertical mixing over the Mid-Atlantic Ridge in the western Atlantic, J. Geophys. Res., 107(C10), 3147, doi:10.1029/2001JC001114, 2002.

\section{Introduction}

[2] The Deep Western Boundary Current (DWBC) of the North Atlantic carries southward North Atlantic Deep Water (NADW) originating in the North Atlantic, specifically from the Subpolar gyre and the Nordic Seas. As the DWBC "turns the corner" around the Caribbean islands and heads south at $20^{\circ} \mathrm{N}$, it enters a comparatively narrow domain between the Windward Islands and the MidAtlantic Ridge which eventually leads to the South Atlantic (Figure 1). In this domain (width $\mathrm{O}(1000 \mathrm{~km})$, length $\mathrm{O}(3000 \mathrm{~km})$ ); the water masses of the DWBC appear to recirculate over the abyssal plains, causing inflated estimates of the strength of the DWBC. Into the domain also enter water masses of southern origin: Antarctic Bottom Water (AABW) at depth as well as Antarctic Intermediate Water/Circumpolar Water (AAIW/CPW) at the intermediate level. Because the domain is as far from the dense water formation regions as it is possible to get in the Atlantic, the water masses have been modified significantly, and exact water mass definitions, by necessity, depend on location and author. Nevertheless, the water masses are clearly distinguishable through their property extrema.

[3] Within each water mass, the properties are relatively uniform across the domain, with one notable exception:

\footnotetext{
${ }^{1}$ Now at Norwegian Meteorological Institute, Oslo, Norway.
}

Copyright 2002 by the American Geophysical Union. 0148-0227/02/2001JC001114\$09.00 over the Mid-Atlantic Ridge. We will in this paper show that property anomalies over the Mid-Atlantic Ridge are not a result simply of lateral advection, but are instead caused by enhanced vertical mixing over the ridge. Furthermore we will estimate the diapycnal mixing coefficient associated with this enhanced vertical mixing.

\section{Methods}

[4] Our approach will be to first analyze conductivitytemperature-depth (CTD) and bottle data to infer circulation, using a set of constraints as guidelines: water particles tend to flow along isopycnals; they tend to conserve their properties if advected; the flow tends to be in thermal wind balance; an advective solution is allowed only if one can identify a pathway from source to sink; and finally, mixing enters as a second-order effect only. From these we infer a circulation scheme for the tropical North Atlantic which involves vertical mixing over the Mid-Atlantic Ridge. This part of the work is covered in section 3. In section 4 we develop a relationship between the vertical gradient of the CTD density profiles and the diapycnal mixing coefficient, utilizing experience gained from the Brazil Basin Tracer Release Experiment [Polzin et al., 1997; Ledwell et al., 2000], where more direct measurements of the mixing were obtained using specialized instrumentation. In section 5 we use that relationship to estimate vertical mixing in the North Atlantic where only shipboard CTD data were available. In section 6 we compare the findings of section 


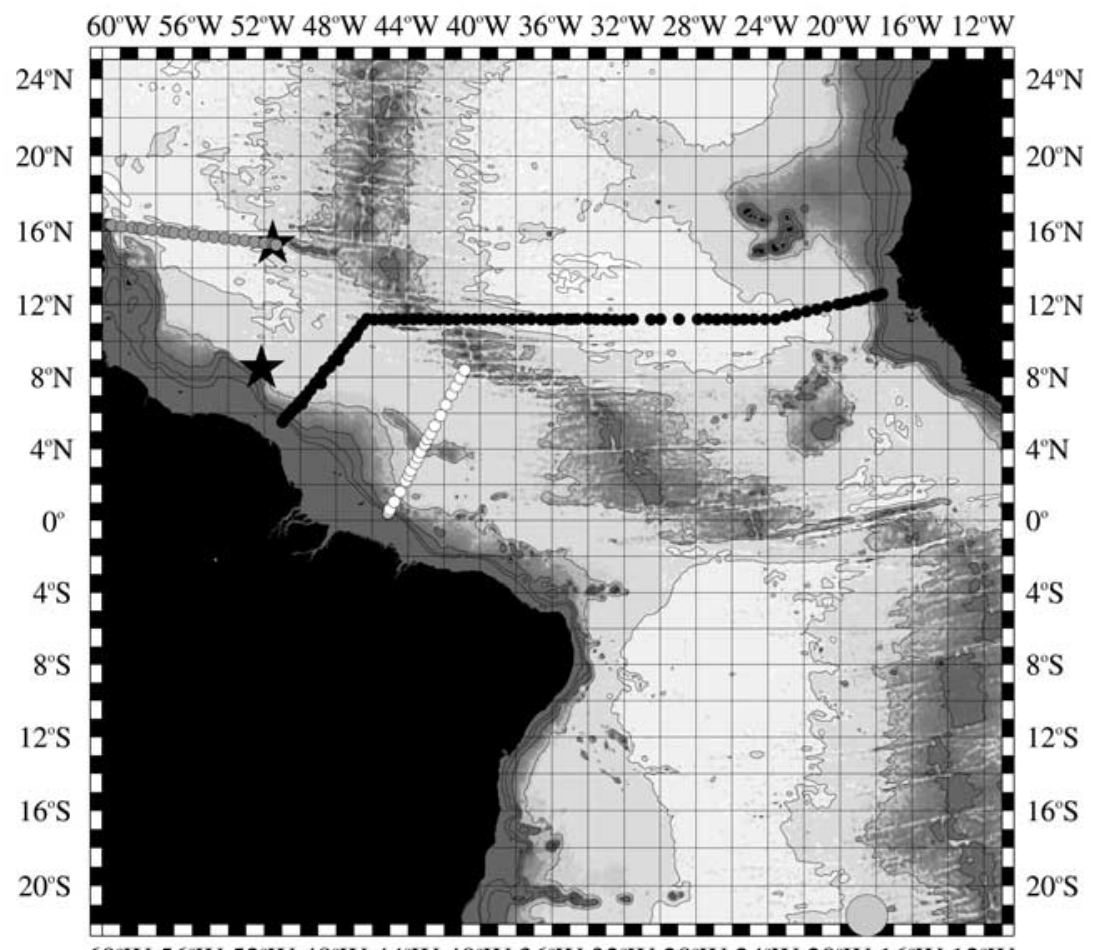

$60^{\circ} \mathrm{W} 56^{\circ} \mathrm{W} 52^{\circ} \mathrm{W} 48^{\circ} \mathrm{W} 44^{\circ} \mathrm{W} 40^{\circ} \mathrm{W} 36^{\circ} \mathrm{W} 32^{\circ} \mathrm{W} 28^{\circ} \mathrm{W} 24^{\circ} \mathrm{W} 20^{\circ} \mathrm{W} 16^{\circ} \mathrm{W} 12^{\circ} \mathrm{W}$

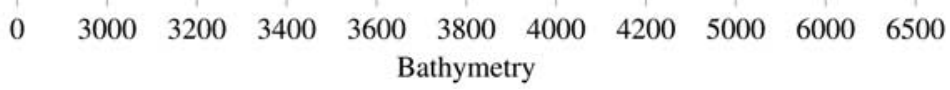

Figure 1. Bathymetry of the tropical western North Atlantic. The location of the hydrographic sections discussed in the text are denoted as follows: white circles, the Ceara Rise section (Figures 2a-2e and 12c); black circles, the Oceanus 205 section (Figures 4, 7, and 12a); and shaded circles, the GAGE section (Figures 5 and 12b). Mooring locations marked with large black stars; the location of the Brazil Basin tracer release is marked with a large shaded circle. Bathymetry is contoured (1000 m intervals) and shaded; note that the color scheme is chosen so as to exaggerate the features of the Mid-Atlantic Ridge.

5 to those of section 3. Finally, the conclusions are presented in section 7 .

\subsection{Data Sets}

[5] The hydrographic data sets used in this study are indicated in Figure 1. Crossing diagonally at $4^{\circ} \mathrm{N}$ is the Ceara Rise section, which is WOCE line AR04 obtained in 1996 on R/V Edwin Link, chief scientist Y. Gouriou. The section nominally at $11^{\circ} \mathrm{N}$ is referred to as the Oceanus 205 section (R/V Oceanus, 1989, chief scientists M. Hall and D. Roemmich). The section at nominally $16^{\circ} \mathrm{N}$ is from a January 2000 CTD survey (R/V Knorr, chief scientists M. McCartney and C. Mauritzen; hereinafter we refer to this line as the GAGE section). (In January 2000 a joint U.S. - German research project named GAGE/ MOVE (GAGE is the U.S. acronym for Guiana Abyssal Gyre Experiment; MOVE is the German acronym for Meridional Overturning Variability Experiment) instrumented 10 current meter moorings spanning the western tropical North Atlantic at nominally $16^{\circ} \mathrm{N}$. In April 2001, 6 current meter moorings were deployed in the Vema Fracture Zone as part of VEX (Vema Exploration Program). The GAGE and VEX moorings will be recovered in 2002 and 2003. Among the goals of these experiments are to quantify the abyssal circulation in the Guiana Basin, with particular emphasis on abyssal recirculations and exchanges between the Guiana and Gambia Basins.) We also use historical data from the tropical Atlantic, especially in the preparation of Figures 6 and 9. For this task we rely heavily on the Hydrobase climatological data base [Curry, 1996].

[6] In the South Atlantic we use the Brazil Basin Tracer Release Experiment (BBTRE) data sets from 1996 and 1997 (in both cases from R/V Seward Johnson, with Jim Ledwell as chief scientist). The physical observations in the Brazil Basin were made both with a shipboard CTD system and with the High Resolution Profiler (HRP) [Schmitt et al., 1988], a specialized fine structure and microstructure instrument. The HRP employs an NBIS MkIII CTD and an acoustic travel time velocimeter is used to infer the horizontal velocity field. The HRP also carries microstructure sensors which return estimates of the centimeter-scale gradient variances of velocity, temperature, and conductivity.

\subsection{Layer Definitions}

[7] In dividing the water column into layers we follow the water mass definitions given by Rhein et al. [1995] 
Table 1. Limits and Characteristics of the Water Masses in the Deep Western Atlantic ${ }^{\mathrm{a}}$

\begin{tabular}{|c|c|c|c|}
\hline $\begin{array}{l}\text { Density } \\
\text { Range }\end{array}$ & Property & Range & $\begin{array}{c}\text { Approximate } \\
\text { Depth Range, m }\end{array}$ \\
\hline $\begin{aligned} \sigma_{1} & >32.15 \\
34.42<\sigma_{1.5} & <34.70 \\
\sigma_{2} & <36.94\end{aligned}$ & $\begin{array}{c}\text { Shallow Upper North } A \\
\theta \\
\text { CFC-11 maximum } \\
\text { S maximum }\end{array}$ & $\begin{array}{c}\text { er }(S U N A D W) \\
3.4^{\circ}-4.5^{\circ} \mathrm{C} \\
34.80-35.00\end{array}$ & $1200-1900$ \\
\hline $\begin{array}{c}34.70<\sigma_{1.5}<34.755 \\
36.94<\sigma_{2}<37.00\end{array}$ & 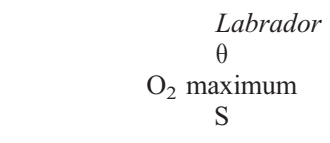 & $\begin{array}{l}2.8^{\circ}-3.4^{\circ} \mathrm{C} \\
34.94-34.98\end{array}$ & $1900-2400$ \\
\hline $\begin{array}{r}\sigma_{1.5}>34.755 \\
\sigma_{2}>37.00 \\
\sigma_{4}<45.83\end{array}$ & $\begin{array}{c}\text { Lower North Atlantic } L \\
\theta \\
\mathrm{O}_{2} \text { minimum } \\
\text { CFC-11 minimum } \\
\mathrm{S}\end{array}$ & $\begin{array}{l}L N A D W-O l d) \\
2.2^{\circ}-2.8^{\circ} \mathrm{C} \\
34.91-34.95\end{array}$ & $2400-3450$ \\
\hline $\begin{array}{l}45.83<\sigma_{4}<45.90 \\
45.83<\sigma_{4}<45.90\end{array}$ & $\begin{array}{r}\text { Overflow Lower North Atlan } \\
\theta \\
\text { CFC-11 maximum } \\
\mathrm{O}_{2} \text { maximum } \\
\mathrm{S}\end{array}$ & $\begin{array}{l}\text { Overflow- } L N A D W) \\
1.75^{\circ}-2.2^{\circ} \mathrm{C} \\
34.85-34.91\end{array}$ & $\begin{array}{l}3450-3900 \\
3450-3900\end{array}$ \\
\hline$\sigma_{4}>45.90$ & $\begin{array}{c}\text { Antarctic Bo } \\
\theta \\
\mathrm{O}_{2} \text { decrease } \\
\mathrm{S} \\
\text { CFC-11 increase }\end{array}$ & $\begin{array}{l}\text { W) } \\
<1.75^{\circ} \mathrm{C} \\
<34.85\end{array}$ & $>3900$ \\
\hline
\end{tabular}

${ }^{\mathrm{a}}$ From Rhein et al. [1995].

(hereinafter referred to as R95). The R95 water mass definitions are listed in Table 1 and indicated as thick gray lines in the Ceara Rise section (Figures $2 \mathrm{a}-2 \mathrm{e}$ ) and subsequent section plots. The water column beneath roughly $1200 \mathrm{~m}$ is divided into five layers. In the potential temperature range $3.4^{\circ}-4.6^{\circ} \mathrm{C}$ is found Shallow Upper North Atlantic Deep Water (SUNADW; Figure 2a). It is characterized by high chlorofluorocarbon (CFC) content (Figure 2b), indicating recent contact with the atmosphere, and it appears to be formed in the boundary current in the western Labrador Sea [Pickart et al., 1997]. In the subtropical Atlantic SUNADW is also indicated by a salinity maximum (Figure $2 \mathrm{c}$ ) and a silica minimum (Figure 2d).

[8] The next layer down is Labrador Seawater (LSW), which is the classical water mass product of the Labrador Sea. LSW experienced reduced production rates in the 1960s and the 1970s [Lazier, 1973, 1988] which would explain why it is less distinguishable in CFC (Figure 2b) than the layer above. Below LSW is found Lower North Atlantic Deep Water-old (LNADW-old), a visibly "old" water mass, as exhibited by a minimum in the CFC distribution (Figure 2b).

[9] R95 identifies the water mass associated with the dense overflows from the Nordic Seas, overflow-Lower North Atlantic Deep Water (overflow LNADW) in the potential temperature range $1.8^{\circ}-2.4^{\circ} \mathrm{C}$ (Figure 2a). Its recent contact with the atmosphere is evidenced by its CFC maximum (Figure 2b) and its oxygen maximum (Figure 2e). Oxygen levels of overflow LNADW exceed $6 \mathrm{ml} / \mathrm{l}$ in the Ceara Rise section. The AABW layer, with potential temperatures less than $1.8^{\circ} \mathrm{C}$ (Figure 2a) is characterized by extremely high silica (Figure 2d) and relatively low oxygen (Figure 2e), salinity (Figure 2c), and CFC (Figure 2b) concentrations.

\section{Inferring Circulation From Hydrography}

[10] The circulation in the tropical Atlantic is by no means virgin territory: as a starting point we lean on a thorough synthesis by Friedrichs and Hall [1993] (hereinafter referred to as FH93). Their scheme was based on geostrophic shear estimates, water property distributions, and mass conservation constraints, and it is reproduced here in Figure 3. They present circulation schemes for four dense layers, roughly comparable to the R95 definitions with one notable exception: Friedrichs and Hall's top layer comprises the top two R95 layers (SUNADW and LSW; we list the FH93 definitions in Table 2 for completeness). In the three upper layers in Figure 3, FH93 shows the DWBC flowing southeastward, hugging the continental slope. A recirculation gyre of magnitude $10 \mathrm{~Sv}\left(1 \mathrm{~Sv}=10^{6} \mathrm{~m}^{2} \mathrm{~s}\right)$, reaching from roughly $18^{\circ} \mathrm{N}$ to the Equator, and offshore to the MidAtlantic Ridge, is clearly indicated within layers 1 and 3 (as well as suggested in layer 2). The net southward transport of deep water is roughly $15 \mathrm{~Sv}$. In the equatorial band, FH93 suggest that part of the DWBC transport is diverted into the eastern basins of the Atlantic through fractures (Chain and Romanche) in the Mid-Atlantic Ridge. Their circulation in layer 2 differs qualitatively from that above and below in that the dominant circulation feature offshore of the DWBC is a net inflow from the South Atlantic, hugging the western flank of the Mid-Atlantic Ridge. In FH93's fourth layer, AABW enters the domain along the Mid-Atlantic Ridge and recirculates in the deepest part of the domain north of the Ceara Rise. In both layers 3 and 4 FH93 show an eastward 


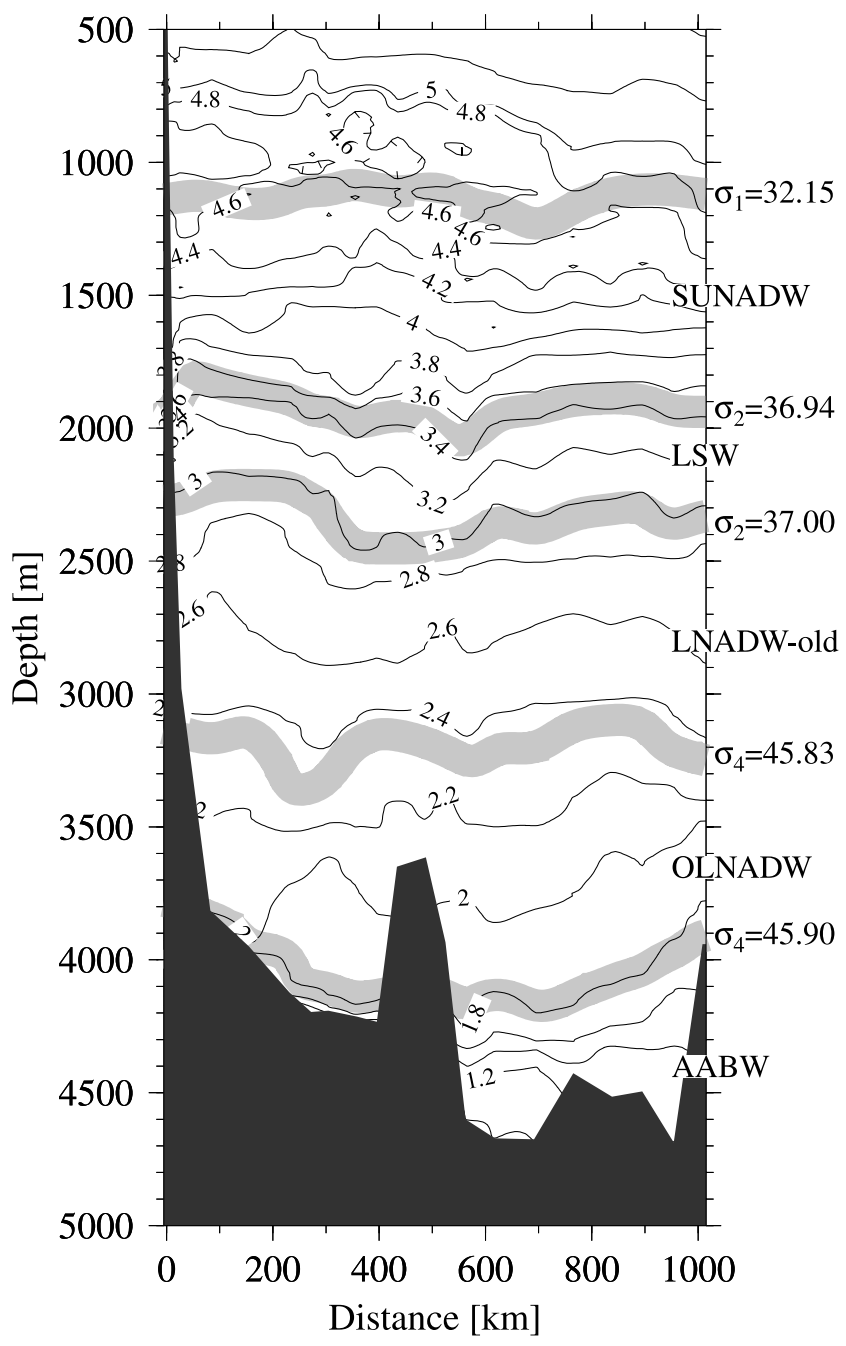

Figure 2a. Potential temperature $\left({ }^{\circ} \mathrm{C}\right)$ for Ceara Rise section. Thick shaded contours are the isopycnals used in the R95 water mass definitions (Table 1): $\sigma_{1}=32.15 ; \sigma_{2}=$ $36.94 ; \sigma_{2}=37.0 ; \sigma_{4}=45.83 ;$ and $\sigma_{4}=45.90$. See location in Figure 1 .

transport through the Vema Fracture Zone at $11^{\circ} \mathrm{N}$, with total magnitude of $4 \mathrm{~Sv}$.

[11] With a strong recirculation gyre in the western North Atlantic between $20^{\circ} \mathrm{N}$ and the equator one might expect that the water mass properties on density surfaces would be fairly uniform across the basin offshore of the DWBC. A careful investigation of the property fields in Figures 2a-2e reveal that the fields are indeed fairly uniform within the various density layers. The most significant departures are found at the eastern end of the section, where contours of CFC (Figure 2b), salinity (Figure 2c), silica (Figure 2d), and oxygen (Figure 2e) sharply rise and cross the isopycnals (the thick gray lines). The isoline uplifts are between $500 \mathrm{~m}$ and $1000 \mathrm{~m}$. This cross-isopycnal uplift near the MidAtlantic Ridge (corresponding to anomalously low salinities, low oxygen, high silica and low CFC content on isopycnals at the Ridge) is a common feature in the tropical domain: as evidence we present two other examples: the Oceanus 205 section (Figure 4) and the GAGE section
(Figure 5) (for simplicity we only show one field. We have chosen silica, because AABW, whose importance shall become evident, is particularly high in silicate). The uplift is particularly evident in the overflow LNADW layer, but it is also noticable in the LNADW-old layer. Other authors have noticed these anomalous conditions over the ridge, and we will refer to these works as appropriate. For instance, Plähn and Rhein [1998] point out, based on a transient tracer box model of the Guiana Basin constrained with CFC measurements, that if the recirculation gyre reached as far east as the Mid-Atlantic Ridge (the Figure 3 scenario) the $\mathrm{CFC}$ values there would have to be much higher, and they suggest that the recirculation pathway therefore cannot extend to the Mid-Atlantic Ridge. However, no one has, to our mind, properly explained the anomalous conditions. We will therefore endeavor to determine how the circulation must deviate from the basin-wide recirculation gyre indicated in Figure 3, considering independently the two layers affected.

\subsection{Overflow Lower North Atlantic Deep Water $\left(\sigma_{4}=45.83-\sigma_{4}=45.90\right)$}

[12] The isopycnal $\sigma_{4}=45.86$ lies in the middle of the overflow LNADW layer; in Figure 6 we present silica on that surface. The data are taken from the Hydrobase climatological data base, and to avoid any misrepresentations due to contouring we have color coded the observations at the spot they were measured. The low silica levels of the overflow waters (purple and dark blue) are evident in the North Atlantic DWBC system, and are seen crossing into the South Atlantic through the equatorial channel at $35^{\circ} \mathrm{W}$. An eastward extension of those low silica values in the equatorial zone is found to $20^{\circ} \mathrm{W}$, in agreement with FH93's equatorial splitting of the DWBC in Figure 3c (we have added a circulation schematic in Figure 6 to indicate the DWBC pathway).

[13] Moving offshore of the DWBC in the Northern Hemisphere, the silica concentrations transition to above $39 \mu \mathrm{mol} / \mathrm{kg}$ (green color coding) as the Mid-Atlantic Ridge is approached. This transition is associated with the sharp uplift of silica contours in the sections presented earlier (Figures 2a-2e, 4, and 5). In silica, the concentration increase is $\mathrm{O}(10 \mu \mathrm{mol} / \mathrm{kg})$. Our goal is to explain what causes this significant spatial gradient in silica (and the associated gradients in oxygen, salinity, and $\mathrm{CFC}$ ). A set of hypotheses can be formulated to explain the properties over the western flank of the Mid-Atlantic Ridge:

- Advection from the eastern North Atlantic, through gaps in the Mid-Atlantic Ridge,

- Advection from the South Atlantic,

- The water is part of, or on the fringe of, the recirculating gyre, but has undergone major transformations due to mixing.

\subsubsection{Hypothesis 1: Advection From the Eastern North Atlantic}

[14] FH93 did take note of the low oxygen level in the midst of their recirculation path (i.e., along the western flank of the Mid-Atlantic Ridge), and suggested that the cause might either be westward flow of "old" dense water from the eastern basin through the Vema Fracture Zone, or vertical mixing with the above-lying waters. The second idea can be discarded quickly, as a mixing with overlying waters would 


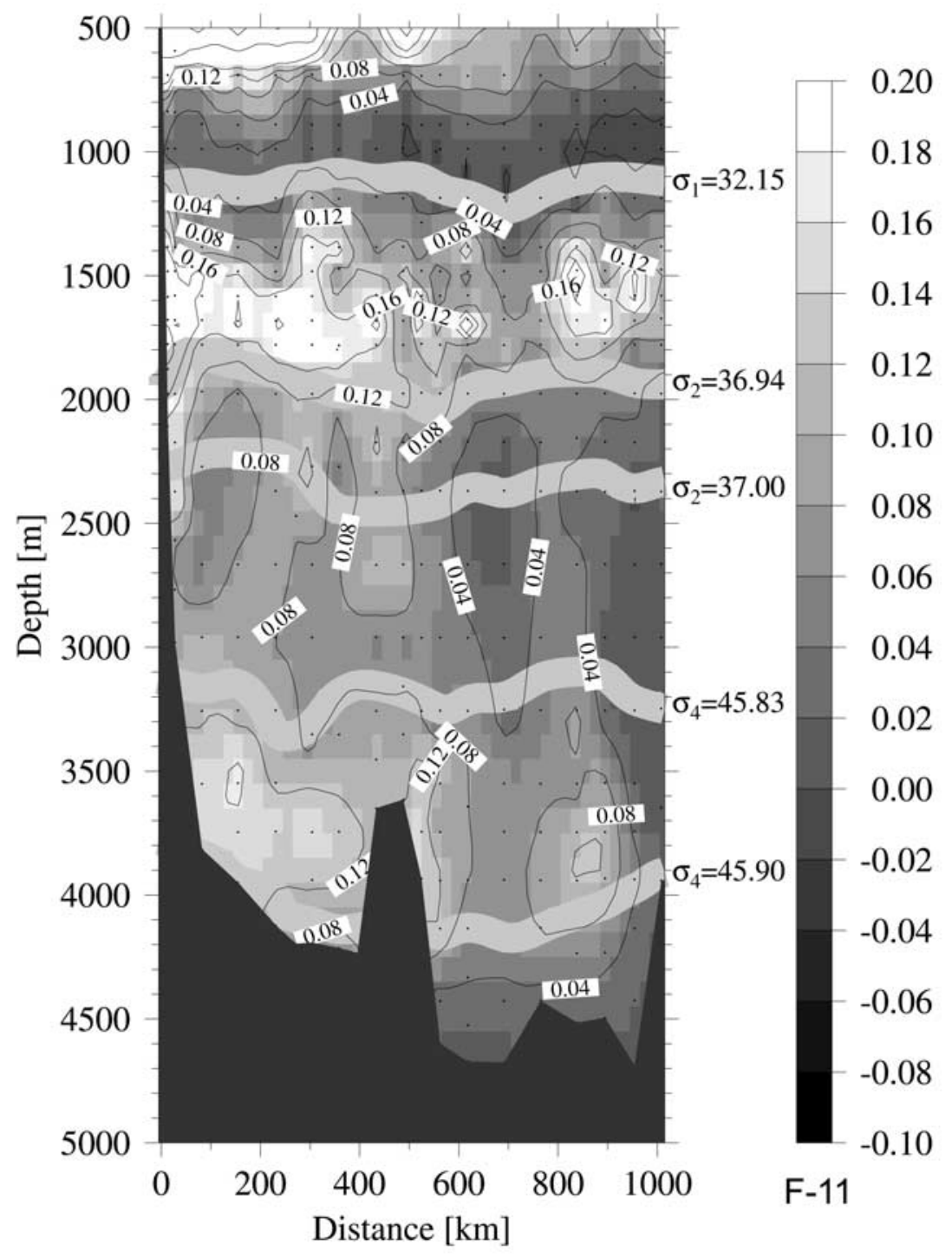

Figure 2b. Freon F-11 (picomole/kg) for Ceara Rise section. Thick shaded contours are defined as in Figure 2a. See location in Figure 1.

cause a decrease, not an increase in silica. However, the former idea requires more careful investigation.

[15] At the Mid-Atlantic Ridge in the tropical domain the overflow LNADW layer is typically found between $3200 \mathrm{~m}$ and 4200-4500 m (see Figures 2a, 4, and 5). The peaks of the Mid-Atlantic Ridge are, typically, shallower than $3000 \mathrm{~m}$. Thus to affect the bulk of the overflow LNADW layer, any westward flow would have to occur in gaps in the Mid-Atlantic Ridge. Two regions stand out in that respect (Figure 1): the Vema Fracture Zone at $11^{\circ} \mathrm{N}$ and a fracture zone simply referred to as the $7^{\circ} 30^{\prime} \mathrm{N}$ Fracture Zone by Arhan et al. [1998]. Both of these fracture zones connect eastern and western waters at depth levels greater than $4000 \mathrm{~m}$. The former has a reported sill depth of $4630 \mathrm{~m}$ near $41^{\circ} \mathrm{W}$ [Vangriesheim, 1980]; the latter has a reported sill depth of $4050 \mathrm{~m}$ near $34^{\circ} \mathrm{W}$ [Arhan et al., 1998]. A current meter array presently deployed in the VFZ, which will be recovered in 2003 (VEX) should yield the best estimate yet of the flow direction and strength for all water masses present there. Until then, the evidence is mainly for eastward flow in that fracture zone: McCartney et al. [1991] estimates an eastward flow of $1.4-1.9 \mathrm{~Sv}$ in the potential temperature range $2^{\circ}-4.5^{\circ} \mathrm{C}$ (this range encompasses all the NADW classes in the FH93 definitions, and reaches up to roughly $1500 \mathrm{~m}$ ), as well as eastward flow (>2 Sv) of AABW. Similarly, Fischer et al. [1996] estimate an eastward flow from the bottom to $3640 \mathrm{~m}$ (which corresponds to roughly $2.1^{\circ} \mathrm{C}$ ) of $2.1-2.4 \mathrm{~Sv}$.

[16] Since these transport calculations are based on limited observations, and since the results for potential temperatures higher than $2.1^{\circ} \mathrm{C}$ are ambiguous, we will compare more closely the properties in the eastern basin to those in the western basin. The Oceanus 205 section presented in Figure 4 extended to the African continent and crossed the Mid-Atlantic Ridge just a short distance north of the Vema Fracture Zone (Figure 1). Evidence of an eastward flow of AABW into the eastern basin is provided by dense, high-silica (Figure 7a), low-salinity (Figure 7b) waters found on the eastern slope of the Mid-Atlantic Ridge in the depth range 4500-6000 $\mathrm{m}$. 


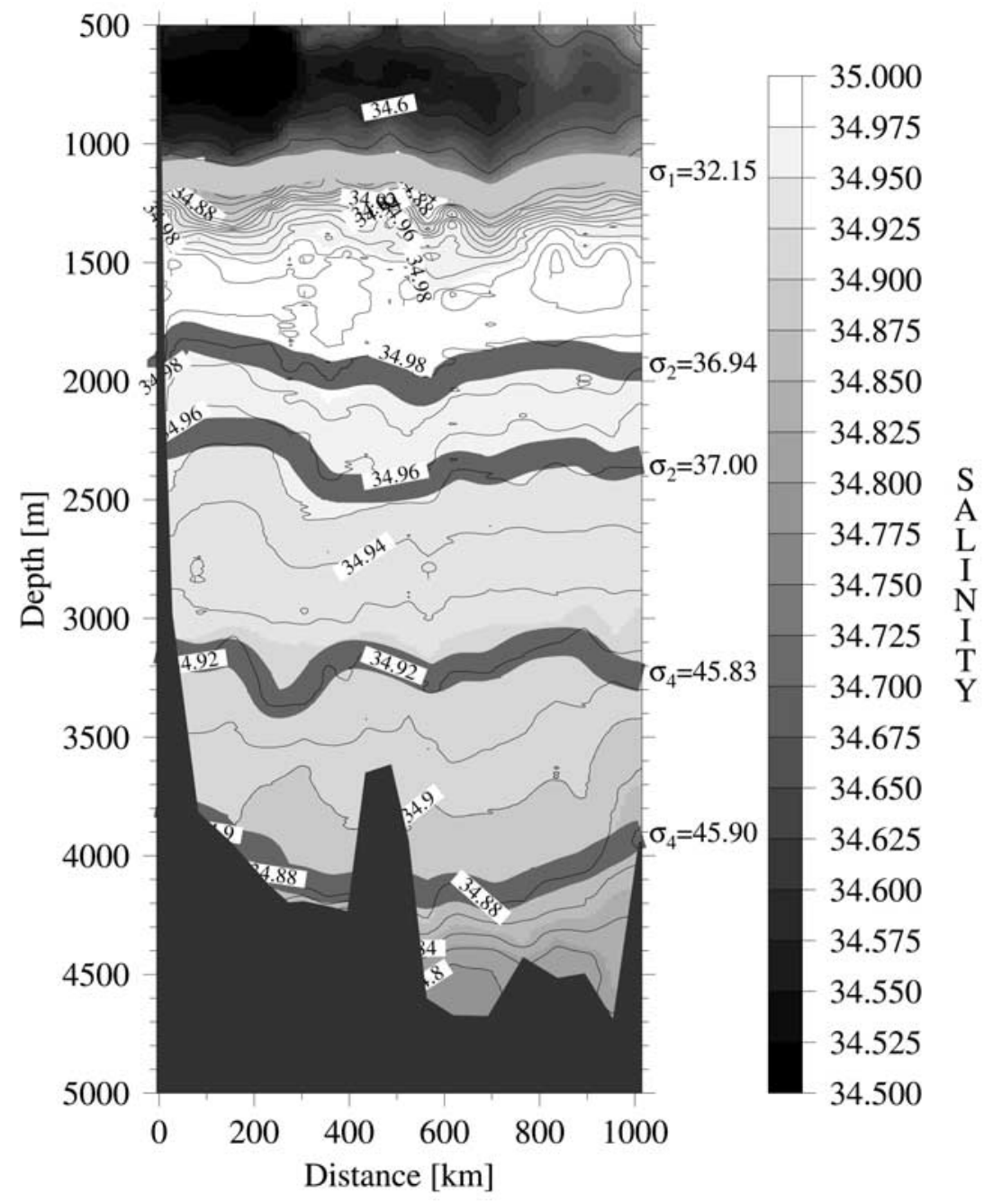

Figure 2c. Salinity (psu) for Ceara Rise section. Thick shaded contours are defined as in Figure 2a. See location in Figure 1.

[17] In these figures the thin contours represent $\sigma_{4}$ isopycnals, and for the deepest density surfaces of the overflow LNADW layer (which also here is bracketed by thick gray lines, the R95 water mass definitions) there is a west-to-east slope, whereas for isopycnals near the top of the layer, the overall east-west density gradient is near zero. If, say, the zonal pressure gradient is zero at the level of the ridge crest, the greater depth of the isopycnals in the eastern basin imply flow from west to east through the gaps in the ridge (assuming friction to break geostrophy), consistent with the observations of flow in the Vema discussed above.

[18] Yet, despite the above indications, can there be a westward flow across the ridge causing the anomalous conditions on the western flank? Such a westward flow would either provide a purely advective source, or mix isopycnally with recirculating overflow LNADW. The silica concentrations (Figure 7a), as well as the salinity levels (Figure $7 b$ ), on a given isopycnal within the overflow LNADW layer are comparable over the western flank of the Mid-Atlantic Ridge to those east of the ridge, whereas in oxygen (Figure 7c) the Mid-Atlantic Ridge resembles a "wall" in water mass properties: on a given overflow LNADW isopycnal the western flank values are distinc- tively intermediate between eastern basin waters and those over the western basin abyssal plains. The same is true for CFC (which are not available for the $11^{\circ} \mathrm{N}$ section, but which were measured during a French 1993 transect crossing the Atlantic at $7.5^{\circ} \mathrm{N}$ ): The eastern basin is devoid of CFCs, whereas the western basin, even on the western flank of the Mid-Atlantic Ridge, show elevated CFCs [see Andrié et al., 1998, Figure 6a]. Considering the potential vorticity field at $11^{\circ} \mathrm{N}$ (Figure $7 \mathrm{~d}$ ), again following a density surface in the overflow LNADW range from east to west one can see a change from intermediate to low (at the eastern slope of the Mid-Atlantic Ridge) to high (on the western slope of the Mid-Atlantic Ridge). Thus it would take a rather unusual mixing scheme to produce the western flank properties from the eastern waters. This hypothetical mixing scheme would require a direct flow from east to west (i.e., very little mixing) for some properties (e.g., silica), whereas for other properties (e.g., oxygen, $\mathrm{CFC}$, and PV) significant mixing would be required between the westward flowing eastern basin waters and the western basin waters. Consequently, we conclude that it is quite unlikely that the source waters for the western flank of the Mid-Atlantic Ridge, in the density range $\sigma_{4}=45.83-45.90$ (overflow 


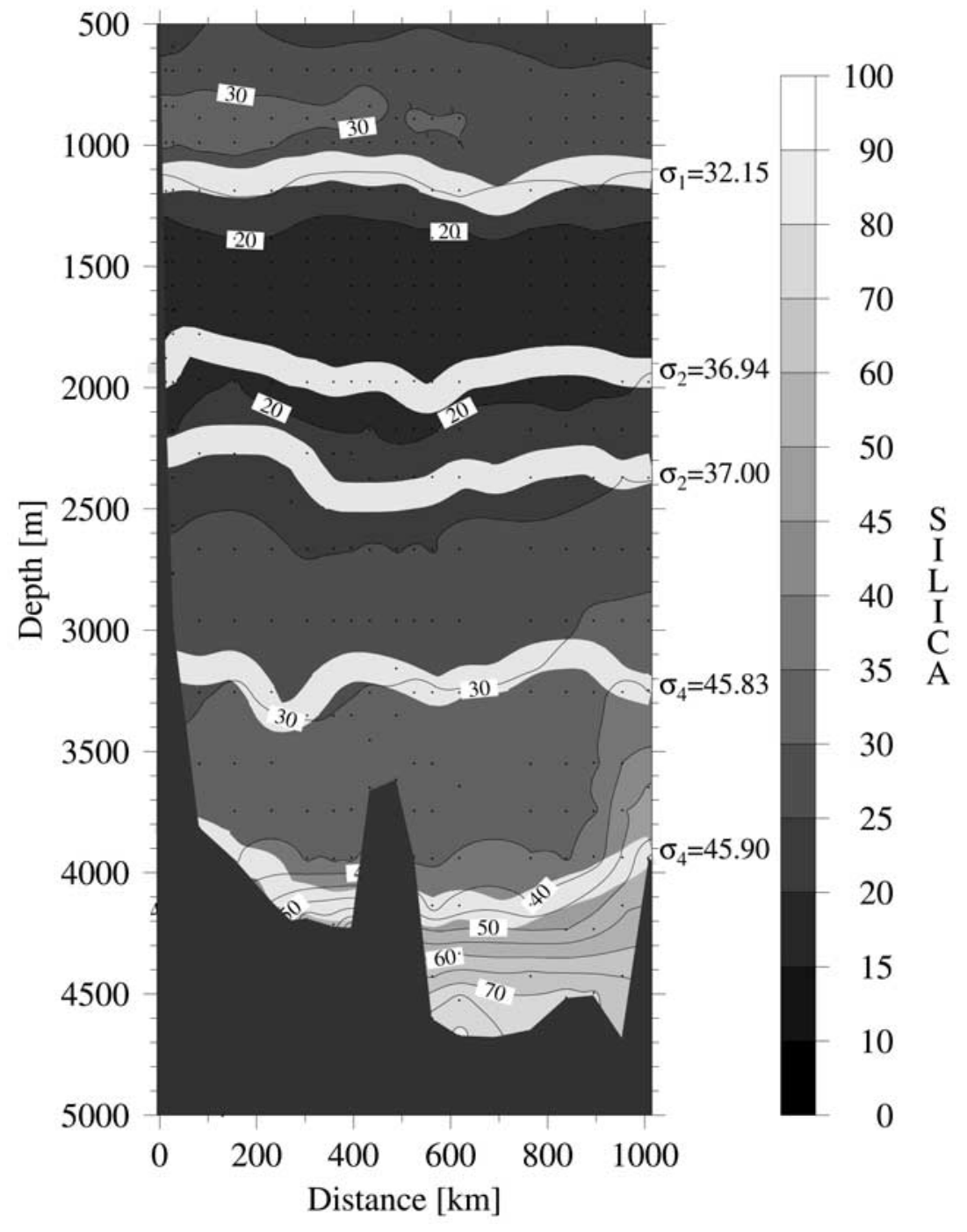

Figure 2d. Silica $(\mu \mathrm{mol} / \mathrm{kg}$ ) for Ceara Rise section. Thick shaded contours are defined as in Figure 2a. See location in Figure 1.

LNADW water) are to be found in the eastern North Atlantic.

3.1.2. Hypothesis 2: Advection From the South Atlantic [19] Since the property levels in the South Atlantic resemble those over the Mid-Atlantic Ridge in the North Atlantic (for instance, the silica levels are elevated there as well), one might hypothesize an advective pathway from the South Atlantic which feeds the anomalous waters over the Mid-Atlantic Ridge in the North Atlantic. Andrié et al. [1999] for instance, noticing the low CFCs over the MidAtlantic Ridge, suggest that the waters over the MidAtlantic Ridge must be imported from the South Atlantic. And indeed, in Figure 6 it is evident that the properties over the western flank of the Mid-Atlantic Ridge are anomalous relative to midbasin values both in the Northern and Southern Hemispheres. On Figure 6 we have indicated, in white, a hypothetical pathway from the South Atlantic.

[20] However, a closer study suggests that such a pathway is not possible. For instance, the silica along the eastern pathway marked in Figure 6 goes from high values in the South Atlantic, through a minimum in the equatorial zone, to intermediate levels in the North Atlantic. That finding is not too surprising: as noted above, part of the Deep Western Boundary Current takes an eastward path in the equatorial zone and feeds the Romanche and Chain Fracture Zones. This was observed directly by a 2 year long current meter mooring deployment during which overflow LNADW fed by the DWBC was observed to flow eastward at a rate of at least 0.4 Sv [Mercier and Speer, 1998]. That pathway is indicated in pink in Figure 6. Any advective pathway in the overflow LNADW density layer from the South Atlantic to the North Atlantic would have to negotiate (1) the relative silica minimum in the equatorial zone (and would therefore require significant mixing) and (2) the eastward flow of the DWBC branch. We therefore deem an advective pathway from the South Atlantic in the overflow LNADW layer unlikely.

\subsubsection{Hypothesis 3: Mixing}

[21] Having excluded the possibility of purely advective sources (tropical recirculations; advective pathway from east; advective pathway from south) we are led to the one remaining viable hypothesis for explaining the anomalous 


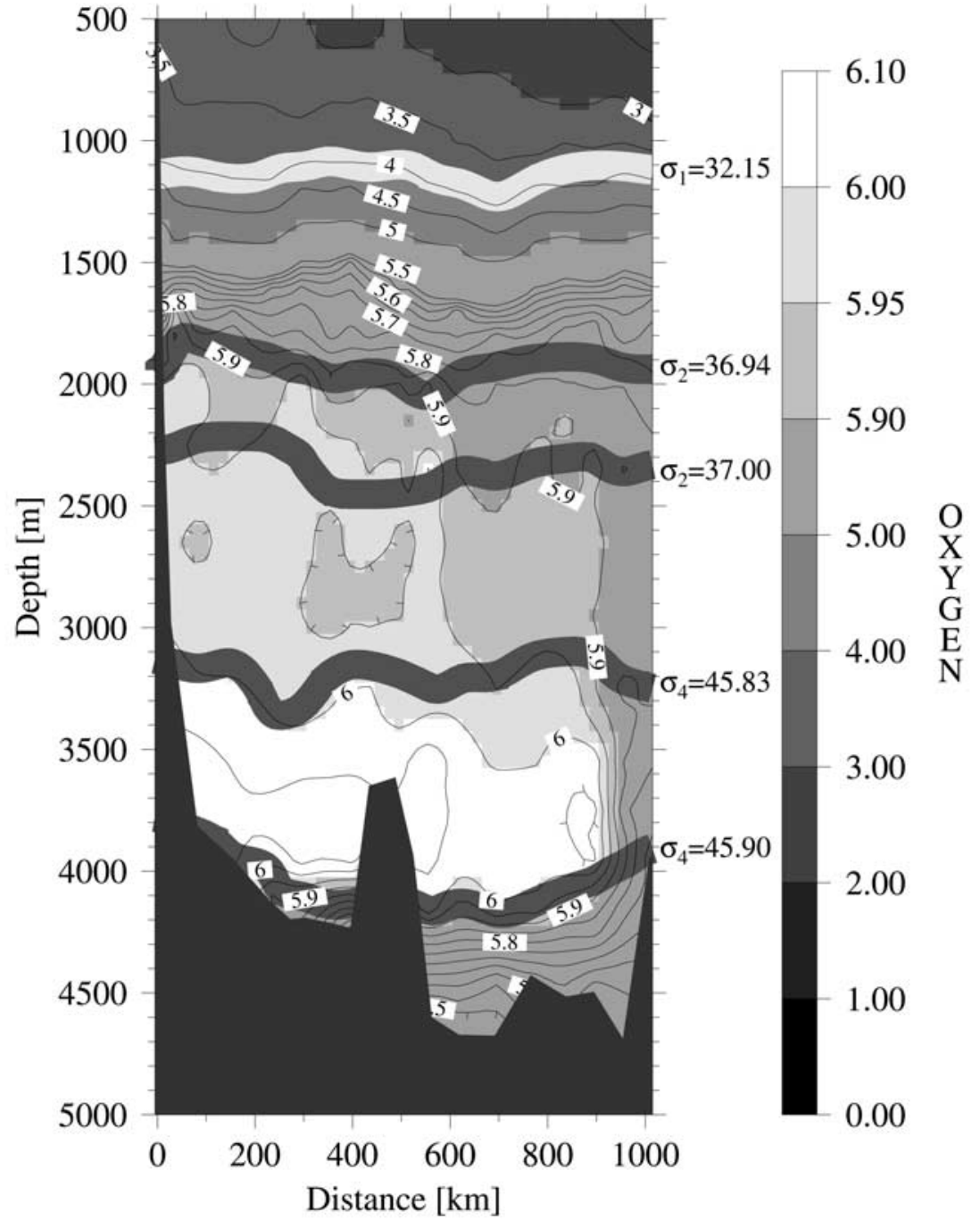

Figure 2e. Oxygen $(\mathrm{ml} / \mathrm{l})$ for Ceara Rise section. Thick shaded contours are defined as in Figure 2a. See location in Figure 1.

conditions within the overflow LNADW layer over the western flank of the Mid-Atlantic Ridge: diapycnal mixing. As noted above, the water property signal cannot be the product of mixing with above-lying waters. But it can be the result of mixing with the AABW layer below because AABW has significantly higher silica, and lower CFCs, oxygen and salinity than the overflow LNADW, yielding anomalously low salinity/CFC/oxygen levels, and increased silica levels, in the overflow LNADW over the Mid-Atlantic Ridge. The possibility of such a mixing scenario for the overflow LNADW layer was hinted at by Speer and McCartney [1991], and we will in section 4 provide further evidence of enhanced vertical mixing over the rough topography associated with the Mid-Atlantic Ridge.

\subsection{Lower North Atlantic Deep Water-Old $\left(\sigma_{4}=37.00-\sigma_{4}=45.83\right)$}

[22] As mentioned, the cross-isopycnal uplift near the Mid-Atlantic Ridge, yielding anomalous water properties on isopycnals over the ridge, is noticable in the LNADW-old layer as well. It is reasonable to assume that since diapycnal mixing was deemed the most likely cause of the anomalous conditions in the overflow LNADW layer, the same is the case for the LNADW-old layer. However, the physical conditions are somewhat different for the LNADW-old layer, so we will consider other possibilities as well. This layer roughly spans the depth range $2500-3200 \mathrm{~m}$ (Figure 7), an interval that straddles the crest of the Mid-Atlantic Ridge, which implies that the ridge provides less of a physical barrier for this layer than for overflow LNADW. We also have to contend with the possibility that hydrothermal venting from the ridge might provide an additional source of anomalous water properties. The set of hypotheses to be considered reads as follows:

- Hydrothermal Venting

- Advection from Eastern North Atlantic

- Advection from South Atlantic

- Mixing

\subsubsection{Hypothesis 1: Hydrothermal Venting}

[23] Hydrothermal activity has been observed in the North Atlantic, for instance at the TAG site in the rift valley of the Mid-Atlantic Ridge at $26^{\circ} \mathrm{N}$ [Rona et al., 1975, 


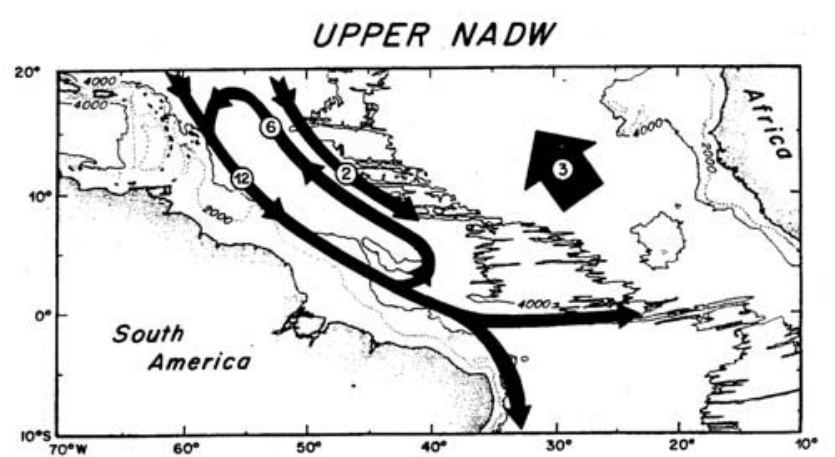

MIDDLE NADW

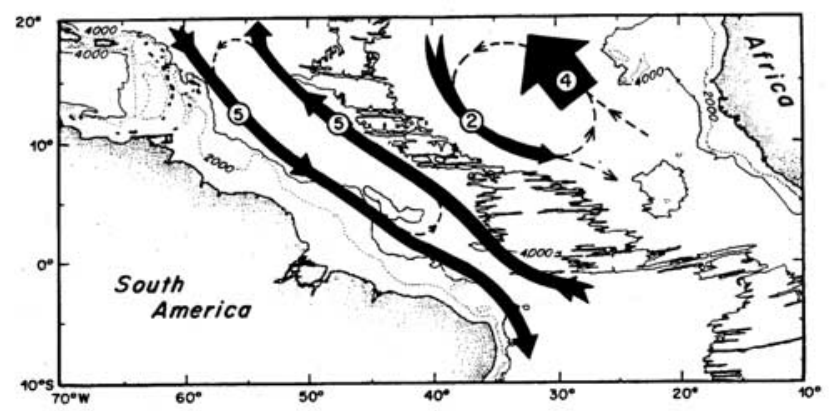

LOWER NADW
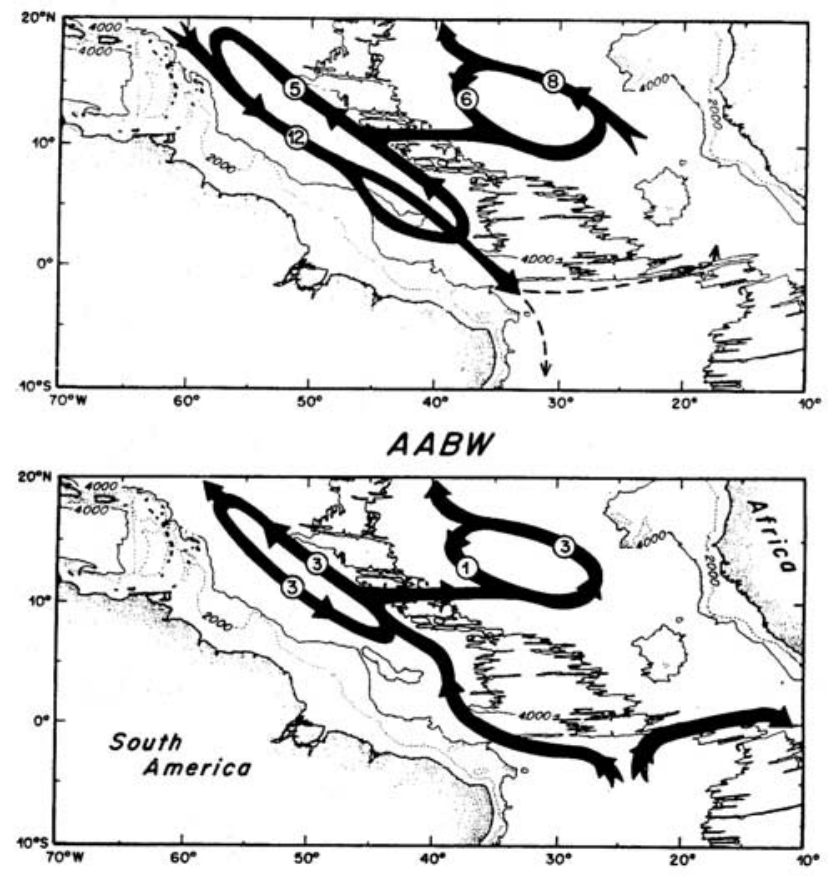

Figure 3. Deep water circulation diagrams, reproduced from FH93.

Jenkins et al., 1980]. The depth range for these vents is 2500-3000 $\mathrm{m}$, which places them at the level of the LNADW-old. Seafloor hot springs might be significantly enriched in dissolved silica because the particulate silica raining down from the surface mixed layer appears to partially dissolve within the benthic layer.

[24] A well-known example of the far reaching effects of hydrothermal venting is given by Lupton and Craig [1981], who show a $\delta^{3} \mathrm{He}$ plume extending $2000 \mathrm{~km}$ to the west of the East Pacific Rise at $15^{\circ} \mathrm{S}$ in the South Pacific Ocean.
The plume is roughly $1000 \mathrm{~m}$ thick, centered at $2500 \mathrm{~m}$, which is a few hundred meters above the crest of the ridge. The silica field at that latitude range is characterized by a silica maximum at roughly $3000-3500 \mathrm{~m}$ (Figure 8), which possibly could be associated with the hydrothermal activity. However, west of the East Pacific Rise within the $\delta^{3} \mathrm{He}$ plume, the silica maximum is extinguished and the silica levels are actually depleted.

[25] In the North Pacific there are in general two silica maxima with depth: one at 2000-2500 $\mathrm{m}$ and one near the seafloor. Talley and Joyce [1992] sought to identify the sources of these silica maxima. In both cases the highest silica values are found in the Northeast Pacific, where high hydrothermal activity occurs at the Juan de Fuca venting region. They nevertheless conclude that hydrothermal venting appears to be far too weak to contribute significantly to the intermediate silica maximum (which they instead attribute to a vertical particle flux divergence) or to the bottom silica maximum (which they attribute to dissolution of sediments). Only in the Cascadia Basin, in the near vicinity of the venting region, do they attribute the increased silica levels at the bottom to hydrothermal activity.

[26] In the Atlantic Ocean, far-field $\sigma^{3} \mathrm{He}$ evidence for hydrothermal activity has been found in the South Atlantic [Rüth et al., 2000]. But in the North Atlantic there is no farfield evidence of hydrothermal activity in the $\sigma^{3} \mathrm{He}$ field (W. J. Jenkins, personal communication, 2001). We therefore have no reason to expect that the elevated silica on the western flank of the North Atlantic Mid-Atlantic Ridge is related to hydrothermal activity.

\subsubsection{Hypothesis 2: Advection From the Eastern}

North Atlantic

[27] Lying at roughly $2900 \mathrm{~m}$, the $\sigma_{3}=41.45$ isopycnal falls in the middle of the LNADW-old layer; in Figure 9 we show silica levels on this isopycnal. The increased silica values near the western flank of the Mid-Atlantic Ridge are evident in the North Atlantic, but these values are not significantly different from those in the eastern Atlantic, a point which was made by Speer [1993]. He referred to this feature as a westward pointing silica tongue on the potential temperature surfaces $2.6^{\circ} \mathrm{C}$ and $3.0^{\circ} \mathrm{C}$ (which are both contained in the LNADW-old layer). Speer made an analogy with the shallower Mediterranean Water salinity tongue, and argued, convincingly, that the silica tongue (in the LNADW-old layer) reflects inflow from the eastern Atlantic. In the ridge-crossing sections of Figure 7 one can see that, in contrast to the layer below,

Table 2. Definitions of Water Masses in Terms of Potential Temperature Classes ${ }^{\mathrm{a}}$

\begin{tabular}{lr}
\hline \multicolumn{1}{c}{ Water Mass } & \multicolumn{1}{c}{$\begin{array}{c}\text { Potential } \\
\text { Temperature }\end{array}$} \\
\hline Surface water & $\begin{array}{r}\theta>24^{\circ} \mathrm{C} \\
\text { Thermocline water }\end{array}$ \\
Lower Thermocline Water & $2^{\circ}<\theta<24^{\circ} \mathrm{C}$ \\
AAIW & $4.7^{\circ}<\theta<12^{\circ} \mathrm{C}$ \\
Upper NADW & $3.2^{\circ} \mathrm{C}$ \\
Middle NADW & $2.4^{\circ}<\theta<3.7^{\circ} \mathrm{C}$ \\
Lower NADW & $1.8^{\circ}<\theta<2.2^{\circ} \mathrm{C}$ \\
AABW & $\theta<1.8^{\circ} \mathrm{C}$ \\
\hline
\end{tabular}

\footnotetext{
${ }^{\mathrm{a}}$ From FH93.
} 


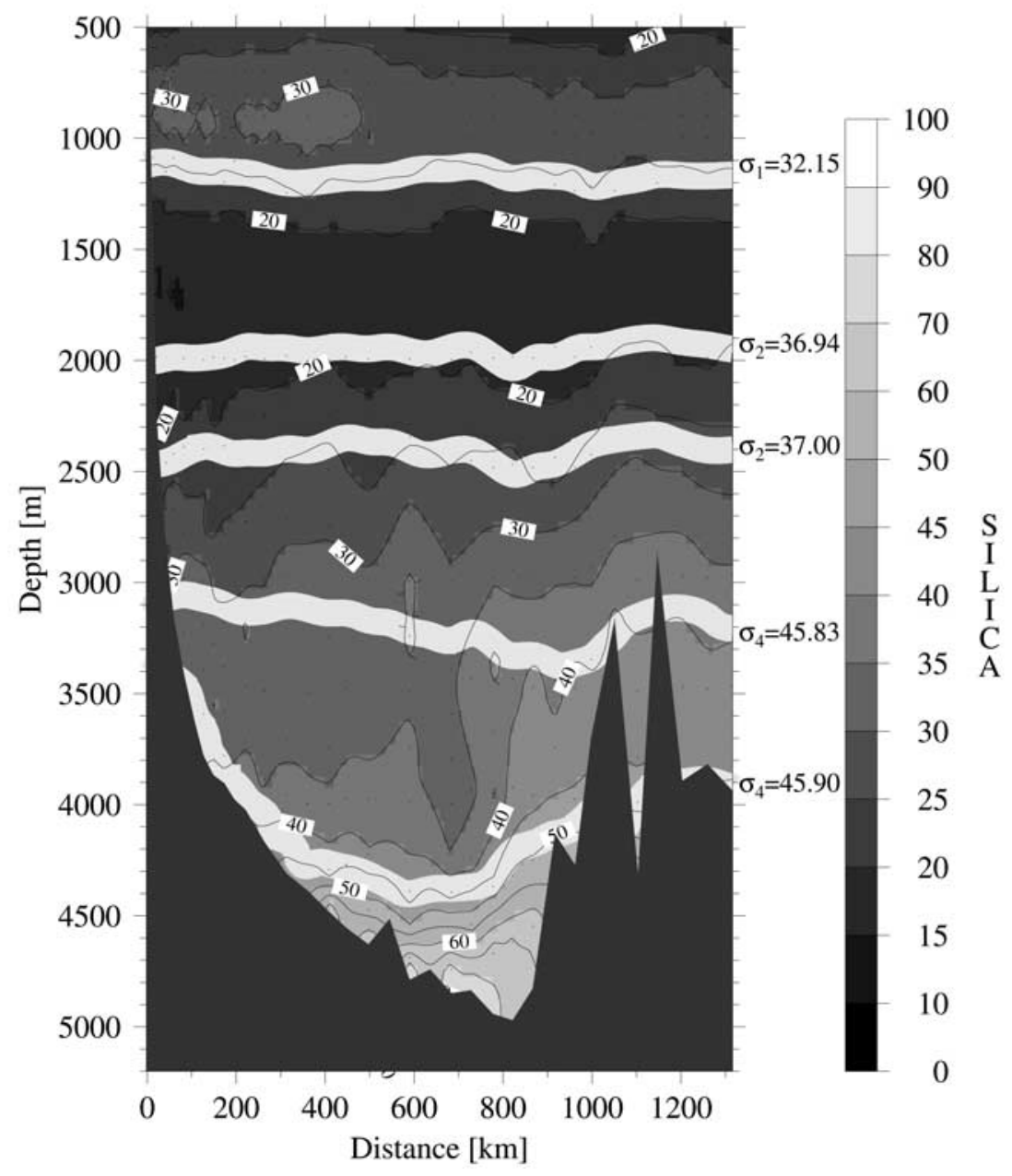

Figure 4. Silica $(\mu \mathrm{mol} / \mathrm{kg})$ for the western basin Oceanus 205 section. Thick shaded contours are defined as in Figure 2a. See location in Figure 1.

westward flow along density surfaces from the eastern basin to the western flank of the Mid-Atlantic Ridge does not require change in any properties. Although the general circulation at intermediate depths in the North Atlantic is not well known, Speer [1993] presents direct evidence from Lagrangian floats and Eulerian current meters for westward flow in this layer, of order $0.1-1 \mathrm{~cm} / \mathrm{s}$. Thus we conclude that westward advection in this layer is a viable hypothesis.

3.2.3. Hypothesis 3: Advection From the South Atlantic

[28] FH93 have an advective path from the South Atlantic included in their circulation scheme (Figure 3) based on the strength of the geostrophic shear and the low oxygen levels in that layer. However, such a hypothesis can be discarded on the same basis it was discarded in the layer below: any flow from the South Atlantic to the North Atlantic has to cross the relative minimum in silica (Figure 9) (and corresponding maximum in oxygen and salinity, not shown) within the equatorial band. Thus such a flow, if it exists, can not be purely advective.

\subsubsection{Hypothesis 4: Mixing}

[29] We will show in section 4 that there is as much evidence for increased vertical mixing over the Mid-Atlantic Ridge in this layer as there is in the overflow LNADW layer in the vertical density gradients. However, in this layer we cannot rule out the strong possibility of advection from the east. In fact, we believe that advection most likely overwhelms any effect of diapycnal mixing.

\section{Estimating Vertical Mixing}

[30] We will next attempt to estimate the magnitude of the diapycnal mixing coefficient despite the fact that microstructure measurements are not available from this region. Instead we are limited to traditional shipboard CTD data. Ferron et al. [1998] had success relating estimates of the Thorpe scale $\mathrm{L}_{\mathrm{T}}$, which is a measure of the vertical length scale of density inversions associated with gravitational instabilities, to the diapycnal mixing coefficient in the Romanche Fracture Zone. The turbulence associated with the sill flows in the Romanche was much more energetic than that typically found above rough bathymetry, implying high signal-to-noise ratios for Ferron et al. [1998]: the Thorpe scales in the high-mixing regions in that study were typically $30-40 \mathrm{~m}$. Over the Mid-Atlantic Ridge, on the other hand, Thorpe displacement scales calculated from traditional CTD data are typically only $5-10 \mathrm{~m}$ (see e.g., Figure 10, showing $\mathrm{L}_{\mathrm{T}}$ for the four easternmost stations of the GAGE section). This is a comparable amplitude to typical ship roll, and cannot be easily distinguished from 


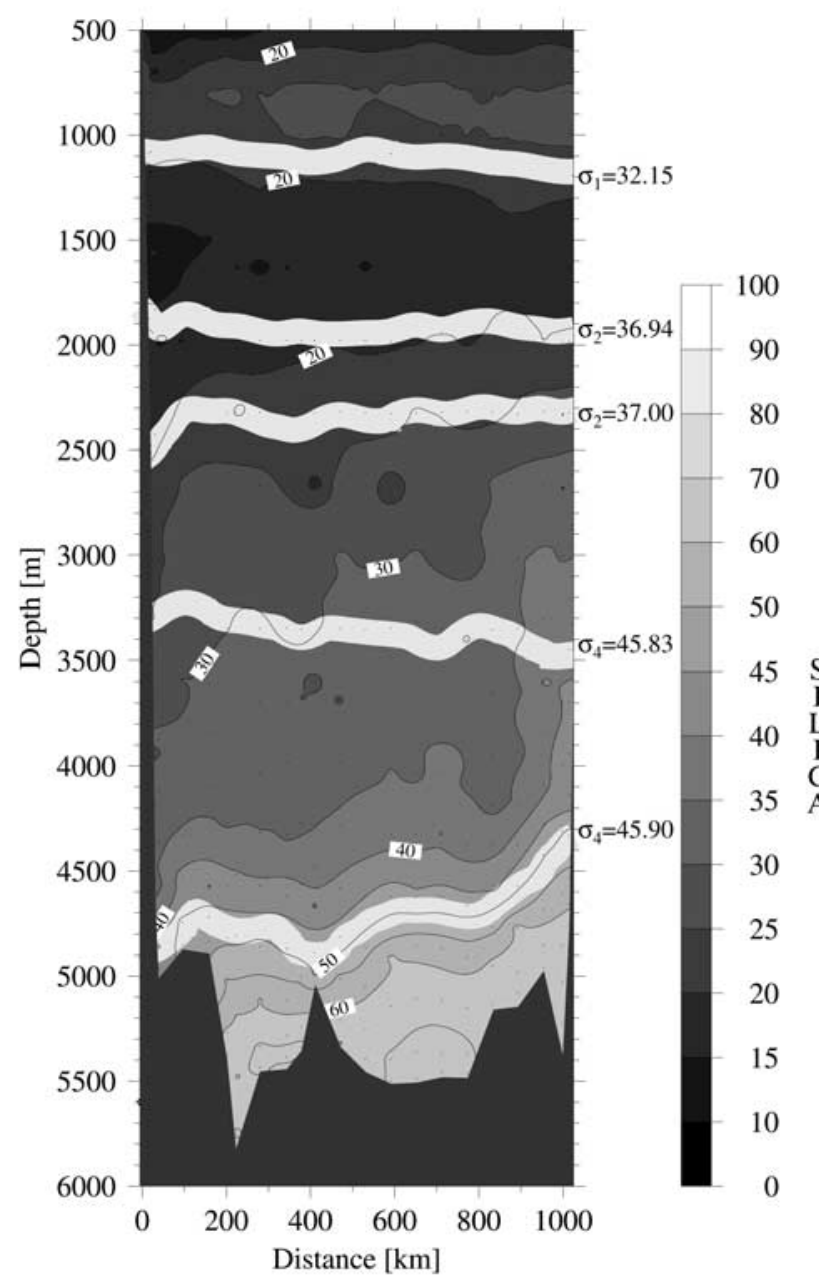

Figure 5. Silica $(\mu \mathrm{mol} / \mathrm{kg})$ for GAGE section. Thick shaded contours are defined as in Figure 2a. See location in Figure 1.

noise. We therefore discarded the Thorpe scale approach for this region.

[31] An alternate approach is to relate the diapycnal mixing coefficient to the spectral density of the strain in the density profile at larger vertical scales [Polzin et al., 1995]. This is what we pursue in the following, taking care to regard signals with vertical length scales less than $10 \mathrm{~m}$ potentially as noise.

\subsection{Results From the Brazil Basin Tracer Release Experiment}

[32] The Brazil Basin Tracer Release Experiment was a joint physical oceanography and tracer study in the South Atlantic Ocean. Its goal was to explore the intensity, spatial distribution and mechanisms of mixing in the deep ocean [Polzin et al., 1997; Ledwell et al., 2000]. A main finding of the study was that turbulence in the abyss had a strong spatial heterogeneity in the basin. As mentioned in section 2, both a shipboard CTD and the HRP was employed in that experiment. The HRP carried its own CTD, which was used to quantify the amplitude of the finescale (vertical wavelengths of ten to hundreds of meters) internal wave field, as well as microstructure sensors which returned estimates of the centimeter-scale gradient variances of velocity, temperature, and conductivity. We will in the following two subsections discuss what information the microstructure and fine structure sensors yielded in terms of turbulent diapycnal mixing. 4.1.1. Microstructure Measurements in the Brazil Basin: Diffusivity Versus Longitude

[33] The microstructure sensors of the free falling HRP can be used to infer diapycnal diffusivity. Turbulent diffusivity estimates are inferred from the velocity gradient estimates using a model that assumes a statistical balance between turbulent production, buoyancy flux, and dissipation [Osborn, 1980]: $K_{\rho}=\Gamma \cdot \varepsilon / N^{2}$, where $K_{\rho}$ is the diapycnal mixing coefficient; $\varepsilon=\varepsilon(d v / d z)$, the rate of dissipation of turbulent kinetic energy; $\Gamma$ is the mixing efficiency; and $N$ is the Brunt-Väisälä frequency.

[34] In the Brazil Basin $K_{\rho}$ was found to be small above the smooth abyssal plains of the central Brazil Basin and the gradual slopes of the South American continental rise, with diapycnal diffusivities of about $0.1 \times 10^{-4} \mathrm{~m}^{2} \mathrm{~s}^{-1}$ [Polzin et al., 1997]. In contrast, turbulent dissipation rates were elevated one to two orders of magnitude above rough topography on the flanks of the Mid-Atlantic Ridge. Those data are presented again here, extended eastward following Toole et al. [1997] with data from an additional cruise to the Brazil Basin a year later [Ledwell et al., 2000] (Figure 11a). As the mixing was found in stratified water remote from the bottom boundary layer, it was further suggested [Polzin et al., 1997] that the bottom generation (and/or scattering) of internal waves and their subsequent propagation, interaction, instability, and breaking was the likely energy source for the turbulent mixing and dictated its distribution with depth.

4.1.2. Fine Structure Measurements in the Brazil Basin: Strain Versus Longitude

[35] We next relate traditional CTD density profiles only (this is what we refer to as fine structure data) to estimates of the diapycnal mixing coefficient measured much more directly with the microstructure measurements discussed above. The link between internal waves and turbulence can be cast as the net downscale transport of energy associated with nonlinear internal wave interactions [e.g., Polzin et al., 1995]. Validation studies suggest that these downscale transports are quadratically dependent upon the buoyancy frequency and finescale shear and strain spectral densities [Gregg, 1989; Polzin et al., 1995]. There is a secondary (albeit not negligible) dependence upon the frequency content of the internal wave field, with larger transports being associated with higher frequency waves. The frequency content of the background wave field [from Garrett and Munk, 1975] (hereinafter referred to as GM) has a near-inertial emphasis with the shear-strain ratio independent of latitude. Consequently, a latitude dependence of the energy transports is implicit in the finescale parameterization scheme for the background wave field. The shear-strain ratio is used by Polzin et al. [1995] as a diagnostic for the departures of frequency content from the GM background. In this study, we are interested in wave fields that depart significantly from the GM description. In particular, we suspect a significant contribution to the finescale fields by semidiurnal internal waves above rough bathymetry, and note that this implies a frequency content independent of latitude. Lacking simultaneous shear and 


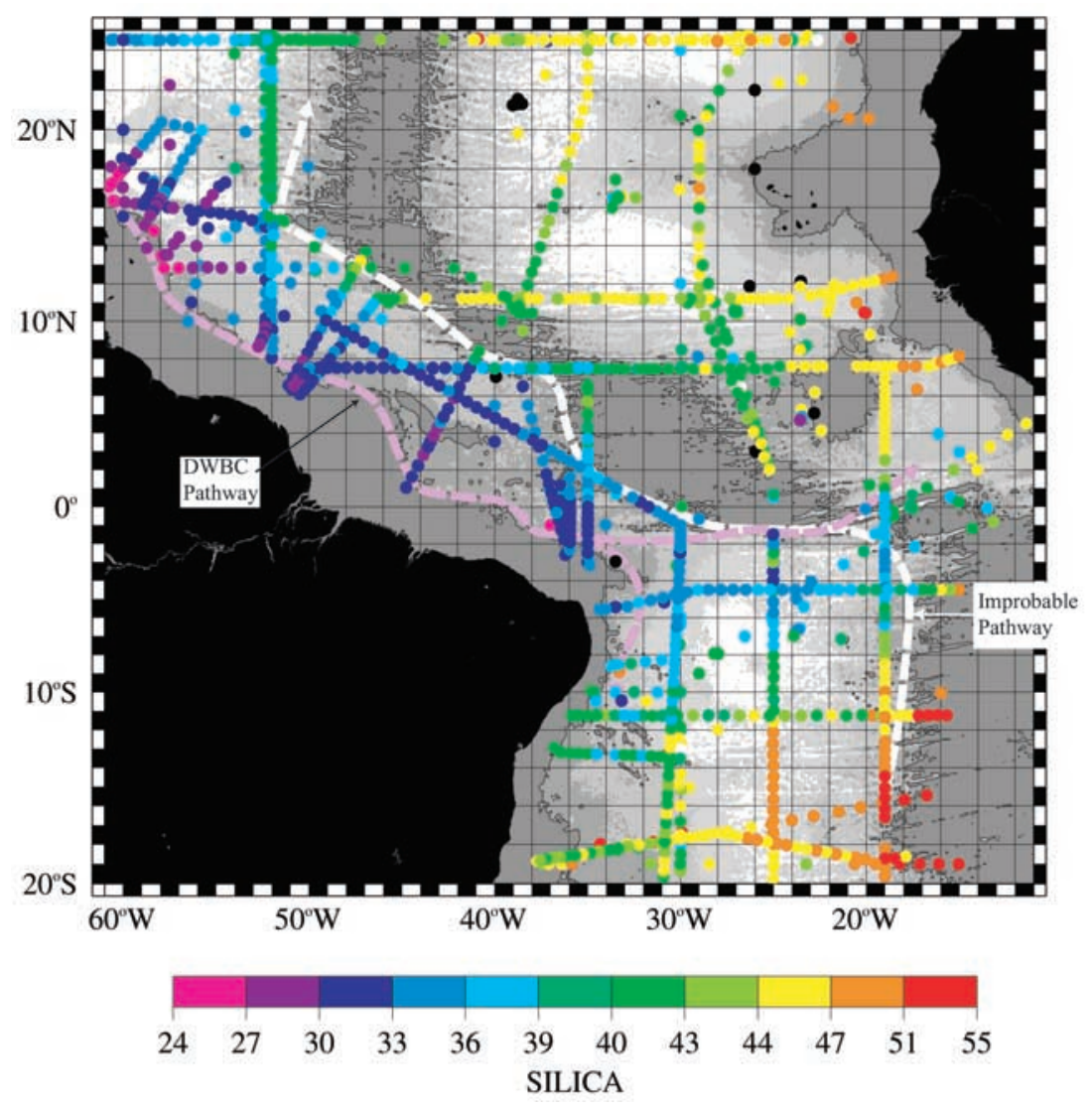

Figure 6. Silica $(\mu \mathrm{mol} / \mathrm{kg})$ on $\sigma_{4}=45.86$ isopycnal. Historical data (including WOCE) collected in the Hydrobase database ([Curry, 1996], updated 2001).

strain estimates which could serve as a diagnostic, in this study we simply employ a latitude-independent measure of turbulent dissipation, $\varepsilon_{\text {equiv }}$, which is equated with the wave transports: $\varepsilon_{\text {equiv }}=7 \times 10^{-10} \mathrm{Wkg}^{-1} N^{2} N_{0}^{-2} \hat{F}_{z}^{2}$, where $\mathrm{N}_{0}$ is $3 \mathrm{cph}$ (the reference $N$ used by GM); $7 \times 10^{-10} \mathrm{~W} \mathrm{~kg}^{-1}$ is the dissipation in the background GM wave field at $\mathrm{N}=\mathrm{N}_{0}$ and $30^{\circ}$ latitude; and $\hat{F}_{z}$ is the strain spectral density, normalized to GM as modified by Cairns and Williams [1976]: $\hat{F}_{z}=\left(F_{z} / \frac{7}{3}\right) \mathrm{cpm}^{-1}$.

[36] To calculate $\mathrm{F}_{\mathrm{z}}$ we evaluate $N^{2}$ variability to estimate strain $\left(\eta_{z}\right)$ as $\eta_{z}=\left(N^{2}-\overline{\left.N^{2}\right)} /\left(\overline{N^{2}}\right)\right.$. Note that strain is nominally defined as the vertical derivative of isopycnal displacement and requires quantifying departures from a time-mean density profile. However, estimates of the time mean are not available from data obtained as part of a hydrographic section. Instead we make the assumption that large vertical length scales in the density profiles represent the time mean and that small vertical length scales represent the internal wave field. Here $\overline{N^{2}}$ is estimated as linear fits to the specific volume anomaly depth profiles using the adiabatic leveling method of Bray and Fofonoff [1981] over approximately $500 \mathrm{~m}$. The vertical aperture for $N^{2}$ is taken as twice the decimation interval of the CTD data. The resulting strain estimate $\eta_{\mathrm{z}}$ was then Fourier transformed to obtain the spectral density $F_{z}$ over the bandwidth $\lambda_{\text {large }} \geq \lambda_{v} \geq \lambda_{\text {small }}$, where $\lambda_{\mathrm{v}}$ is the vertical wavelength; $\lambda_{\text {large }}=320 \mathrm{~m}$ (or $256 \mathrm{~m}$, depending on the decimation interval of the CTD data); and $\lambda_{\text {small }}=50 \mathrm{~m}$. This bandwidth represents a pragmatic compromise: The parameterization presented by Polzin et al. [1995] assumes data that resolves a high wave number spectral cutoff, $m_{c}$, defined by $\int_{i}^{m_{i}} S_{z}(m) d m=0.7 N^{2}$, which occurs at a $10 \mathrm{~m}$ vertical wavelength for the GM spectrum $\left(S_{z}(\mathrm{~m})\right.$ is the shear spectrum). At the low wave number end of the bandwidth, choosing $\lambda_{\text {large }}$ too small results in a biased estimate of $\mathrm{m}_{\mathrm{c}}$. On the other hand, in a vertically inhomogeneous wave field, too large a value of $\lambda_{\text {large }}$ will result in a biased estimate of the dissipation, though in the opposite sense. (The parameterization given by Polzin et al. [1995], which was developed for a statistically homogeneous wave field, relates dissipation $\varepsilon$ to the square of the shear spectral density. Using fine structure data, one can only estimate an average spectrum over a finite depth interval. If the spectral density varies in space it is not true that the average square of the spectrum is equal to the square of the average spectrum. Thus in an inhomogeneous wave field the average spectrum calculated from the CTD data will provide a biased estimated of the average squared shear spectrum and thus of the dissipation $\varepsilon$. By reducing the depth range over which the spectrum is computed, the data are spatially more homogeneous and the bias is therefore reduced.) At the high wave number end of the bandwidth, choosing $\lambda_{\text {small }}$ equal to $1 / \mathrm{m}_{\mathrm{c}}$ in the background wave field will introduce noise induced by package motion at surface wave swell periods. We compared rosette-mounted CTD data and coincident HRP CTD data from the Brazil Basin Experiment and found that with a cutoff of $\lambda_{\text {small }}=50 \mathrm{~m}$ the two instruments yield 

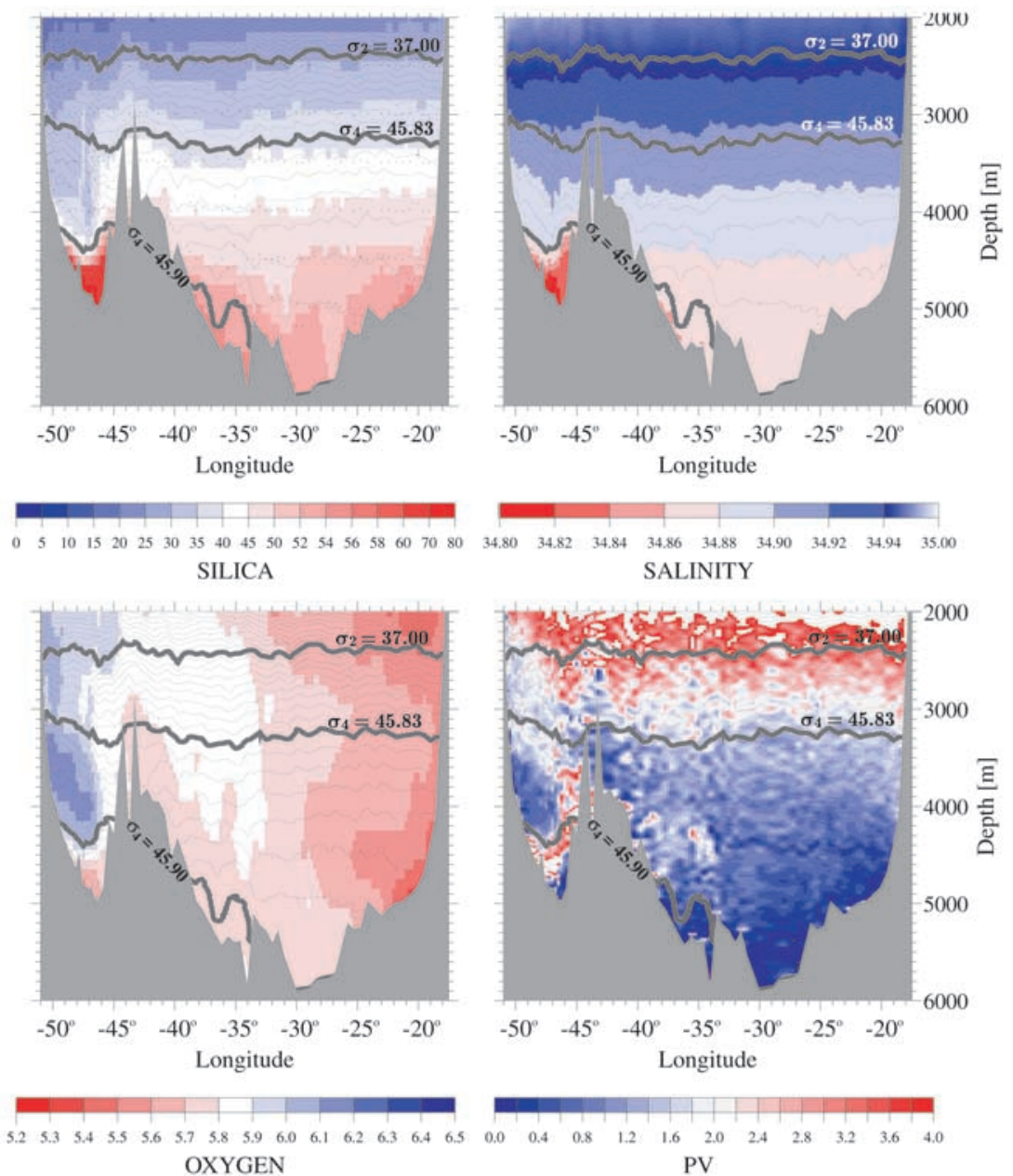
OXYGEN

Figure 7. Full Oceanus 205 section: (a) silica ( $\mu \mathrm{mol} / \mathrm{kg}$ ), (b) salinity, (c) oxygen (ml/l), and (d) potential vorticity $\left(1 \times 10^{12} \mathrm{~m}^{-4} \mathrm{~s}^{-1}\right)$. Contours are $\sigma$ isolines. Thick shaded contours are potential density lines (R95; Table 1) bracketing the overflow LNADW layer. See location in Figure 1.

comparable results. Concerns about biasing the estimate by including wave numbers larger than $\mathrm{m}_{\mathrm{c}}$ [Gargett, 1991] are not as important for strain as for shear spectra as shear spectra roll off more quickly than strain spectra [Polzin et al., 2002]. In the end, however, the justification for using any particular bandwidth lies in an empirical relationship between fine structure and microstructure, as will be exhibited in Figures 11a and $11 \mathrm{~b}$ below.

[37] Finally, the association between internal waves and turbulent mixing is obtained by normalizing $F_{z}$ and using the relationship $\mathrm{K} \rho \cong \Gamma \cdot \varepsilon_{\text {equiv }} / N^{2}$, with $\Gamma=0.2$, yielding:

$$
K_{\rho}=0.05 \times 10^{-4} \hat{F}_{z}^{2} m^{2} s^{-1} .
$$

The spectral density estimates are shown in Figure 11b, and can be compared to Figure 11a. While the mapping is not one-to-one (one can infer from Polzin et al. [1995] that approximately $2000 \mathrm{~m}$ of data are needed in order to obtain factor of 2 confidence intervals), the density fine structure estimate is clearly able to replicate the pattern of spatial variability evident in the microstructure data.

[38] The strain variance can be interpreted as a measure of the squashing and separation of isopycnals associated with differential displacements by internal waves. A more intuitive notion of (1) can be had by analogy to the surface wave field. Say, for instance, that one was interested in quantifying the fraction of the sea surface covered by whitecaps. One wouldn't necessarily be interested in the displacement of the sea surface, which is dominated by swell and typically does not break. Rather, it is the smaller-scale wind wave field which dominates the RMS sea surface slope and is more directly related to instability conditions associated with whitecapping. In terms of predicting the whitecapping fraction, a reasonable attempt would need to contain information on the spatial gradients of the sea surface. The strain variance is an analogous quantification of the spatial gradients in the internal wave field.

\section{Estimates of Vertical Mixing in the North Atlantic, Using Fine Structure Data}

[39] With the association between finescale strain and microstructure apparent in HRP data from the South Atlantic made in section 4.1, we ask whether similar patterns can be found in CTD fine structure data from the abyssal North Atlantic. The answer is yes: the pattern of 


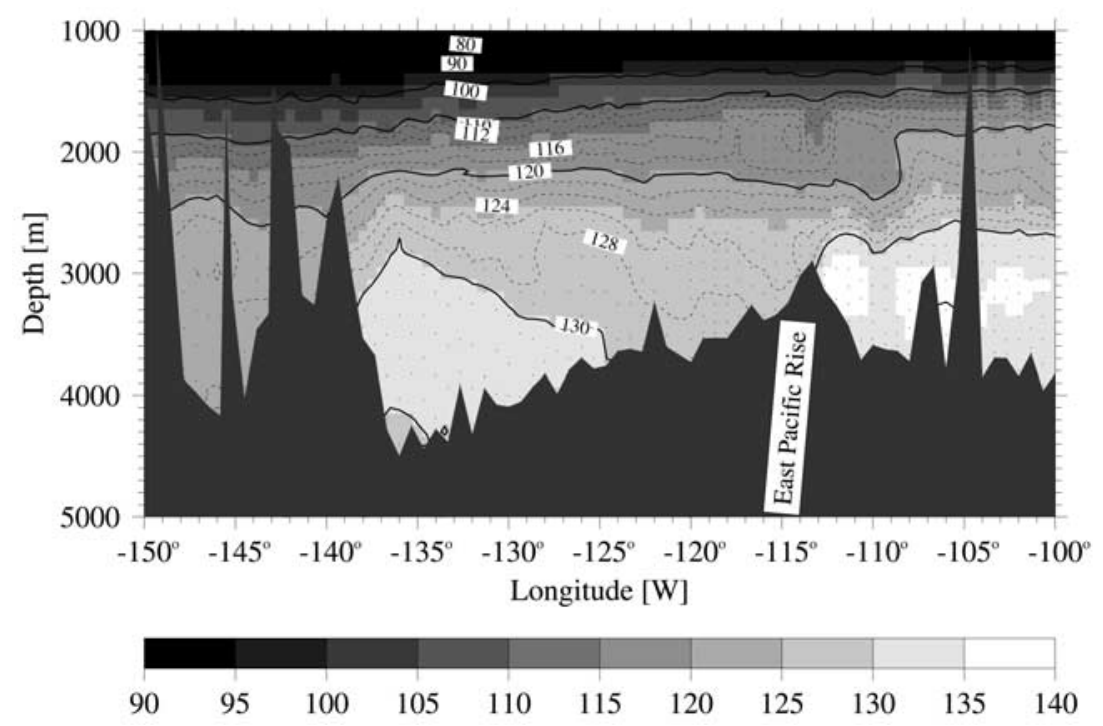

Figure 8. Silica ( $\mu \mathrm{mol} / \mathrm{kg})$ along $17^{\circ} \mathrm{S}$ in the South Pacific. R/V Melville 1994.

low values at thermocline levels and a deep enhancement in over the Mid-Atlantic Ridge is evident in the Oceanus 205 section (Figure 12a), in a section combining the GAGE section in the west with historical data crossing the MidAtlantic Ridge (Figure 12b), and in the Ceara Rise section (Figure 12c; the enhancement is evident in the two easternmost stations). Also quantitatively the North Atlantic region compares well to the Brazil Basin: the inferred intensity of vertical mixing over the Mid-Atlantic Ridge is as strong in the North Atlantic as it is in the South Atlantic. [40] West of the Mid-Atlantic Ridge, over the abyssal plains, the North Atlantic strain field does not fall to background GM values, as it does in the Brazil Basin. Instead, moderately enhanced fine structure is apparent over the abyssal plains in the North Atlantic data (compare Figure $11 b$ to Figures $12 \mathrm{a}, 12 \mathrm{~b}$, and 12c). We suspect that the difference lies partly in the fact that the topography of the abyssal North Atlantic is not as smooth as the Brazil Basin, and partly in that the Northern Hemisphere basin is much narrower than the Brazil Basin so the abyssal plains are in not in the far field of possible internal wave sources at the Mid-Atlantic Ridge.

[41] Further west, over the continental slope in the Deep Western Boundary Current domain, all three Northern Hemisphere sections (Figures 12a, 12b, and 12c) show enhanced strain. For this feature we cannot compare to the Brazil Basin as that study did not sample the western boundary region. However, such an enhanced signal was found on the continental slope of the Mid-Atlantic Bight during the TWIST experiment at $36.5^{\circ} \mathrm{N}$, where microstructure and fine structure data were obtained (depth range $500-1800 \mathrm{~m}$ ) [Toole et al., 2000]. In that experiment the enhancement was associated with flow over small-scale topography superimposed on the continental slope. We therefore expect that the fine structure enhancement seen over the continental slope in Figures $12 \mathrm{a}, 12 \mathrm{~b}$, and $12 \mathrm{c}$ corresponds to enhancement of vertical mixing there.

[42] Perhaps the most striking feature of the Ceara Rise section (Figure 12c) is the pattern of enhanced strain variance throughout the water column between the Ceara
Rise $\left(43^{\circ} \mathrm{W}\right)$ and the continental slope. This pattern does not fit easily into patterns apparent in existing microstructure data, so we withhold judgment on the interpretation of this feature. We do note that the apparent enhanced strain here may reflect the presence of quasi-permanent density fine structure [e.g., Polzin et al., 2002] associated with the intermingling of water masses in that region or equatorially trapped finescale planetary waves rather than enhanced internal wave energy.

[43] To summarize, the fine structure data in the North Atlantic indicate enhanced vertical mixing over the MidAtlantic Ridge, reaching well above the ridge crest up to

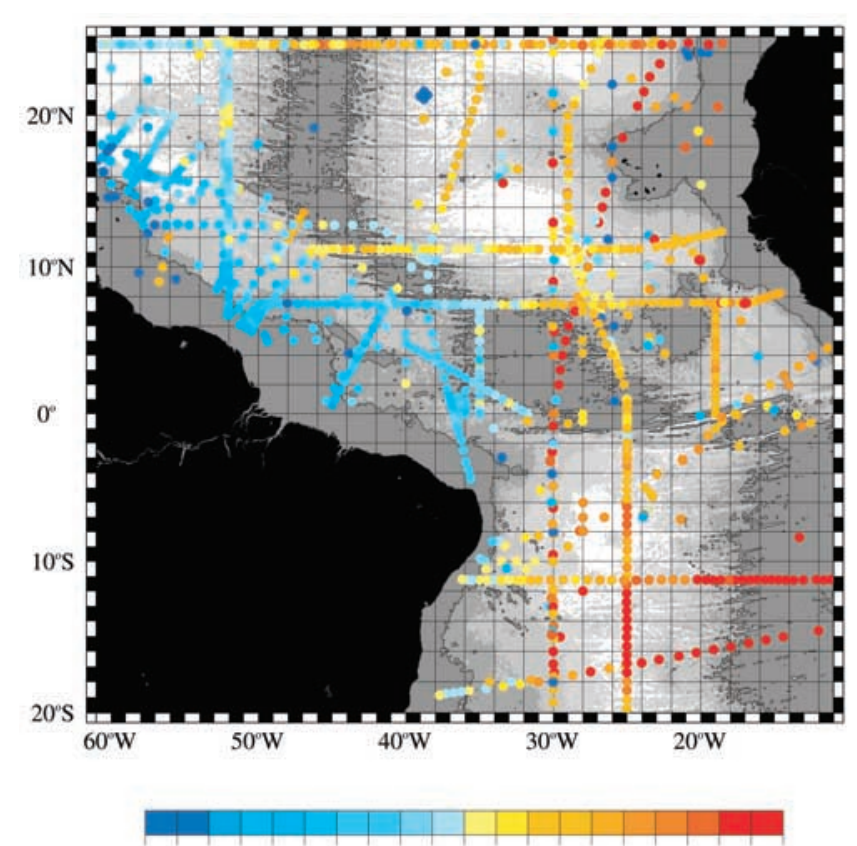

202122232425262728293031323334353637383940

Figure 9. Silica $(\mu \mathrm{mol} / \mathrm{kg})$ on $\sigma_{3}=41.45$ isopycnal. Historical data (including WOCE) collected in the Hydrobase database ([Curry, 1996], updated 2001). 


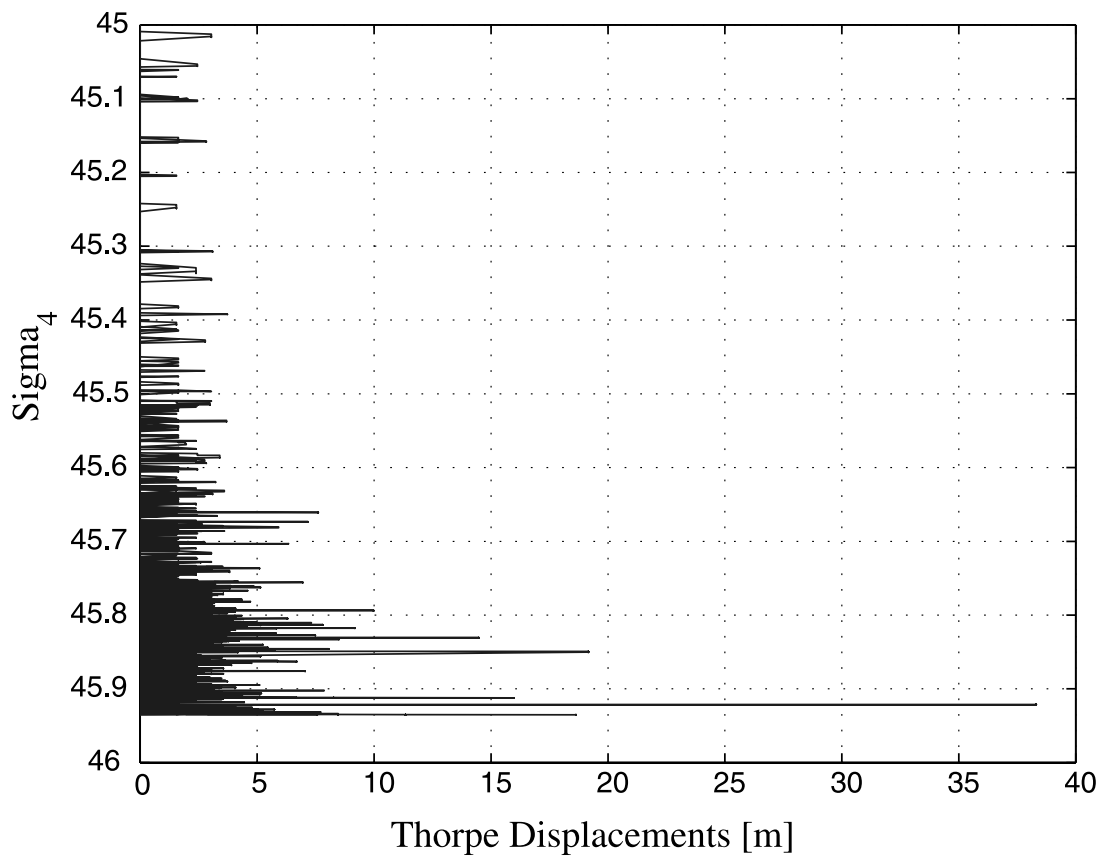

Figure 10. Thorpe displacement scales $(\mathrm{m})$ plotted versus $\sigma_{4}$ for the easternmost GAGE stations.

typically $2000 \mathrm{~m}$. The data also show greatly enhanced vertical mixing over the continental slope.

\section{Fine Structure Measurements Versus Hydrography}

[44] The finding of anomalous hydrographic property distributions over the western flank of the Mid-Atlantic Ridge were the original motivation for this work. The crossisopycnal uplift in isolines of silica occurs where strain measurements show an increase toward the Mid-Atlantic Ridge. To better visualize this we have overlaid silica contour lines on the Oceanus 205 section (Figure 12a): note the uplift of the 35 and 40 isolines toward the Mid-Atlantic Ridge where the strain is enhanced. The same effect is seen on the easternmost two stations of the Ceara Rise section (Figures $2 \mathrm{~d}$ and 12c). Note also in the Oceanus 205 section (Figure $12 \mathrm{a}$, in which between-station bathymetry data is plotted) that the uplift in silica and inferred vertical mixing truly occurs where the roughness in topography changes.

[45] Another feature of the Oceanus 205 section is that further up in the water column the silica uplift seems to reach farther west (see Figure 4, depth range 3000-3500 m; see also Figure 2e). This feature may reflect a zonal circulation cell associated with the mixing near the MidAtlantic Ridge. In the Brazil Basin Experiment it was found that the circulation scheme was better represented by a three-dimensional rather than a one-dimensional pattern, in the following sense: The enhanced vertical mixing above the rough topography of the Mid-Atlantic Ridge is strongly bottom intensified, and a diapycnal advection-diffusion balance [McDougall, 1991] can be used to relate the bottom intensification of the mixing to diapycnal downwelling above the Mid-Atlantic Ridge. Increasing downwelling as the bottom is approached implies vortex-stretching and consequent poleward motion, consistent with the observed motion of the tracer above rough topography [Ledwell et al., 2000]. The abyssal zonal circulation is completed by "upwelling" flow (dense-to-light across isopycnals) toward the Mid-Atlantic Ridge crest in deep canyons associated with zonally oriented offset fractures, again consistent with the observed motion of the tracer within the canyons. The net result is a zonal overturning circulation with Bottom Water being transported to the ridge crest, being transformed while in the canyons into a lighter, warmer water class by turbulent processes, and exiting back into the abyssal interior at shallower depths closer to the ridge crest. The zonal part of this circulation, quantified as a stream function estimate from an inverse model [St. Laurent et al., 2001], is shown in Figure 11a.

[46] As discussed above, in the Northern Hemisphere data, enhanced mixing is indicated not only over the MidAtlantic Ridge but also over the continental slope. Yet the nutrient fields in the DWBC show no indications of mixing across water mass boundaries (see Figures 2e, 4, and 5). We do, as mentioned above, feel confident that the signature of increased vertical mixing in the DWBC is real, and we have to question what differences there are between the DWBC and Mid-Atlantic Ridge regions that cause mixing not to be as evident in the hydrography in the former region as it is in the latter.

[47] One difference relates to horizontal scale: the spatial scale of the continental slope is quite small because the slope is steep compared to that of the Mid-Atlantic Ridge, as is evident in Figure 1. In Figure 12b we had to expand the horizontal scale tenfold to be able to show the high levels of fine structure over the continental slope. So mixing over the continental slope would need to be orders of magnitude more intense in order to match the broad Mid-Atlantic Ridge in terms of large-scale impact.

[48] Another difference lies in advection speed: advection in the DWBC may dominate any mixing that occurs such 

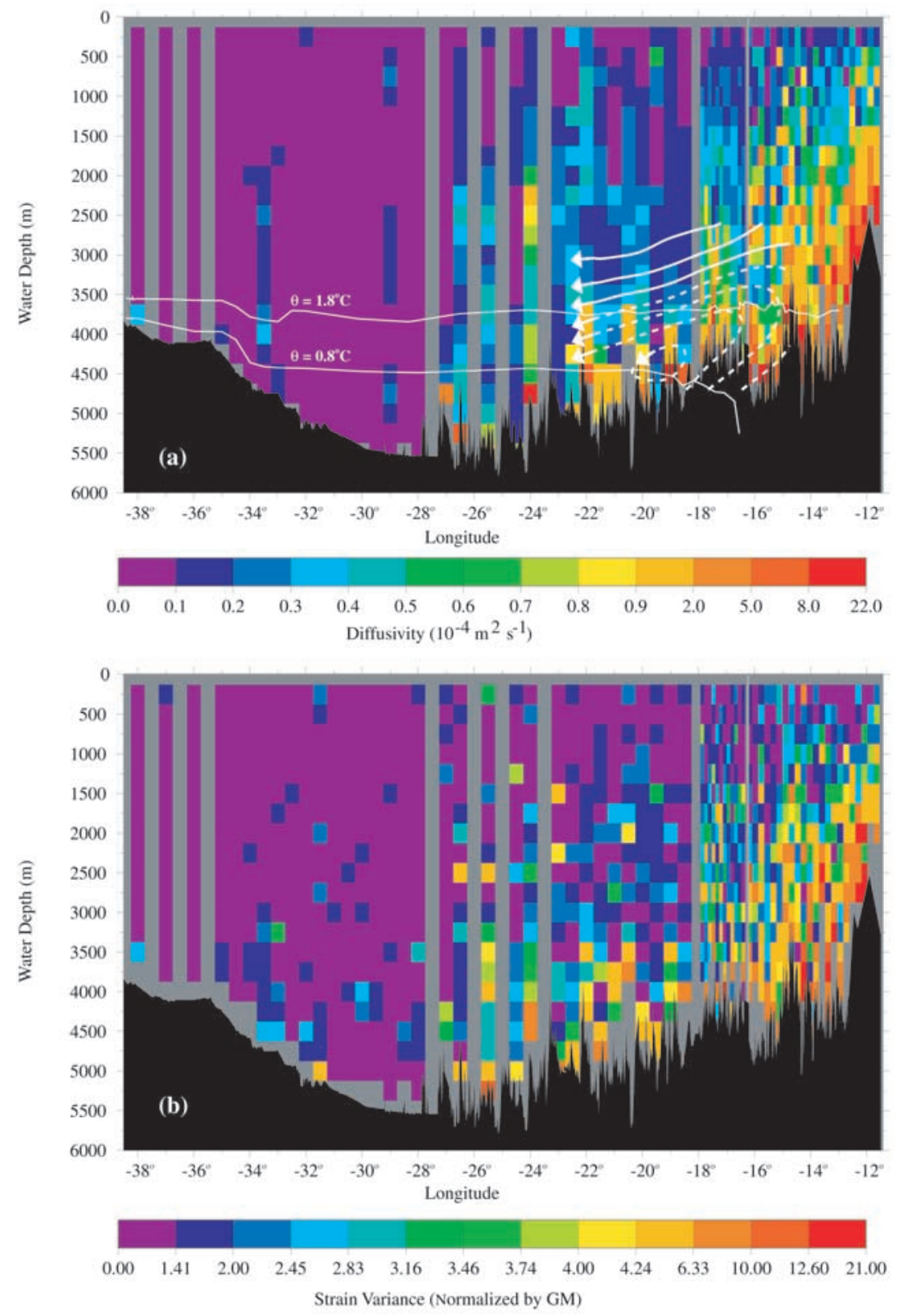

Figure 11. (a) Depth-longitude section of cross-isopycnal diffusivity $K_{v}$ in the Brazil Basin inferred from velocity microstructure observations ([Polzin et al., 1997]; with additional data from a later cruise [Ledwell et al., 2000] added). Note the nonuniform color map. The thin white lines mark the observed depths of the $0.8^{\circ} \mathrm{C}$ and $1.8^{\circ} \mathrm{C}$ isotherms. The thicker white lines with arrows are a schematic representation of the stream function estimated from an inverse calculation [St. Laurent et al., 2001] and are intended to portray the zonal overturning circulation and modification of Bottom Water in the Brazil Basin. Each distance bin represents an individual profile. (b) Depth-longitude section of density fine structure, with contour levels selected to map the fine structure onto the microstructure data in Figure 11a (equation 1). For instance, purple hues in Figure $11 \mathrm{~b}$ correspond to diffusivities $K_{v}=0.1 \times 10^{-4}$ $\mathrm{m}^{2} \mathrm{~s}^{-1}$ in Figure 11a. Data were obtained from the freely falling High-Resolution Profiler as part of the Brazil Basin Tracer Release Experiment. Each depth bin represents a centered estimate from a single spectrum having a piece length of $512 \mathrm{~m}$.

that any local evidence of mixing is quickly swept away. To quantify that statement we will compare the velocity fields in the DWBC to those over the western flank of the MidAtlantic Ridge. Although there have been virtually no measurements of the velocity fields in the vicinity of the Mid-Atlantic Ridge (the closest are probably the Polymode clusters A, B, and C [Tarbell, 1980], all situated well off the flank), the easternmost GAGE/MOVE mooring (deployed near the easternmost CTD station in Figure 5) was recovered and reset by Uwe Send and his group in Kiel in early 2001. We compare these results to a one-year record at $8^{\circ} 30^{\prime} \mathrm{N}$ in the DWBC [Johns et al., 1993] (see Figure 1 for 

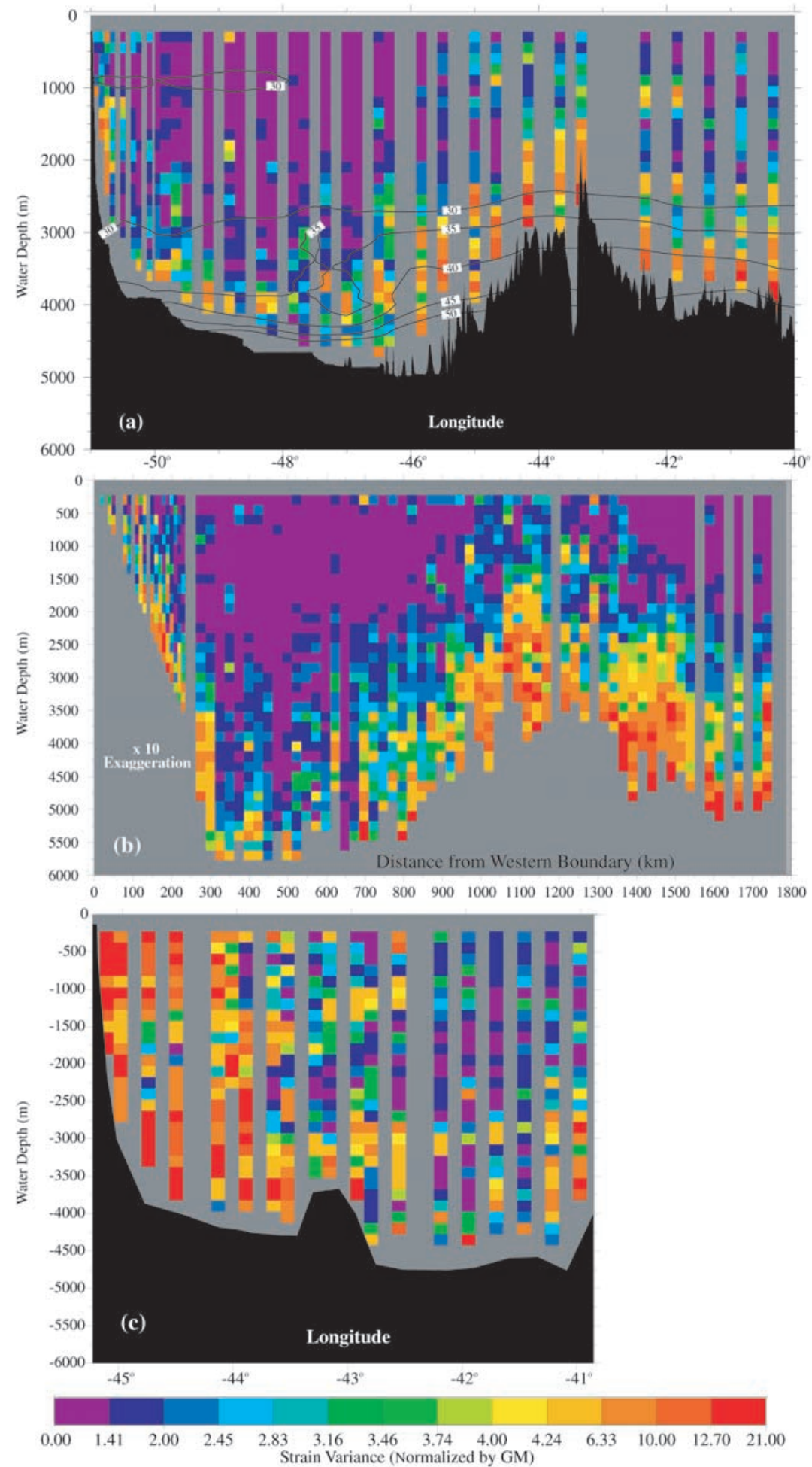

Figure 12. (a) As in Figure 11b, except that the data are from the Oceanus 205 hydrographic section. The bottom profile is underway bathymetry recorded at $5 \mathrm{~min}$ (time) intervals. Silica contours are overlaid. (b) Depth-distance from the western boundary section of density fine structure. The contour levels are identical to those in Figures 11b. CTD data from the GAGE experiment and from the Hydrobase historical database ([Curry, 1996], updated 2001) are employed. The historical data are contained within a box having corners at $\left(10^{\circ} \mathrm{N}, 54^{\circ} \mathrm{W}\right)$ and $\left(16^{\circ} \mathrm{N}, 36^{\circ} \mathrm{W}\right)$. The western boundary coordinate is defined as the distance normal to a line running from $\left(8^{\circ} \mathrm{N}, 52^{\circ} \mathrm{W}\right)$ to $\left(20^{\circ} \mathrm{N}, 64^{\circ} \mathrm{W}\right)$. The profiles extend to the deepest depth bin of any individual profile in a given distance bin: each distance bin may represent multiple profiles. Piece lengths of $640 \mathrm{~m}$ were utilized with the historical data having decimation interval of $10 \mathrm{~m}$. (c) As in Figure 11b, except that the data are from the Ceara Rise section. 
mooring locations). The moorings within the overflow LNADW layer in the DWBC (at $3840 \mathrm{~m}$ and $4340 \mathrm{~m}$ ) both measured mean speeds higher that $20 \mathrm{~cm} / \mathrm{s}$ (maximum mean speed was $27 \mathrm{~cm} / \mathrm{s}$ at $4340 \mathrm{~m}$ ), directed toward southeast, along the isobaths. The moorings in the overflow LNADW layer over the Mid-Atlantic Ridge (at $3610 \mathrm{~m}$ and $4109 \mathrm{~m}$ ) measured $2.1 \mathrm{~cm} / \mathrm{s}$ and $3.2 \mathrm{~cm} / \mathrm{s}$, respectively. The direction was north-northwest. Thus from our limited amount of comparable data, the velocities appear to be at least five times higher in the western boundary current than over the western flank of the Mid-Atlantic Ridge.

\section{Conclusions}

[49] We have sought to explain the anomalous hydrographic conditions in the abyssal layers over the western flank of the Mid-Atlantic Ridge in the North Atlantic. The anomalous hydrographic conditions are a ubiquitous feature of the Mid-Atlantic Ridge region, seen both in the tropics and the extratropics. For the overflow Lower North Atlantic Deep Water layer we deduce, by eliminating the possibility of advective sources, that the conditions must be caused by vertical mixing of Antarctic Bottom Water upwards in the water column, resulting in lowered oxygen and CFC levels, and increased nutrient levels. For the Lower North Atlantic Deep Water-old layer above, on the other hand, we regard advection from the eastern North Atlantic as a primary cause for the anomalous conditions.

[50] We have furthermore sought to quantify the mixing coefficient associated with this vertical mixing. Using strain variance in CTD density profiles we find evidence for enhanced vertical mixing over the Mid-Atlantic Ridge, as compared to the abyssal plains to the west. The inferred levels of vertical diffusivities over the Mid-Atlantic Ridge are as high as in the South Atlantic: $1-10 \times 10^{-4} \mathrm{~m}^{2} / \mathrm{s}$.

[51] The purpose of the ongoing GAGE experiment is to quantify the strength of the abyssal recirculation inferred from hydrography in the Guiana Basin, which appears in the CFC fields to close upon itself a distance off the MidAtlantic Ridge, as discussed earlier. The enhanced mixing, and thus increased vertical velocities and vortex stretching, that we have diagnosed over the Mid-Atlantic Ridge imply horizontal velocities. In a planetary vorticity budget these velocities are poleward, as was indeed found in the tracers released in the Brazil Basin Experiment [Ledwell et al., 2000]. It is therefore intriguing to speculate that there exists a causal link between internal wave-driven mixing and the recirculation gyre itself, a possibility that calls for further investigations. In such a scenario the recirculation is basinwide, but due to the enhanced vertical mixing with AABW the hydrographic properties in the overflow LNADW over the Mid-Atlantic Ridge are significantly diluted, so for instance the CFC tracer core of the recirculation appears west of the Mid-Atlantic Ridge. We acknowledge that such a scenario was deemed unlikely in the modeling study by Plähn and Rhein [1998], but one can imagine that by testing a wider range of parameters with a truly threedimensional advection-diffusion model the results might come out differently.

[52] Acknowledgments. We would like to express gratitude to the captain and crew of the R/V Knorr, for their excellent execution of the
GAGE deployment cruise in January 2000. We thank Uwe Send for contributing the first-year current meter data from the easternmost GAGE/ MOVE mooring. We thank Mindy Hall for giving us access to the original Oceanus 205 data, and we thank Pascal Morin and Philippe JeanBaptiste for giving us access to CITHER-1 data. We thank Lou St. Laurent for providing the zonal overturning stream function in Figure 11a and John Toole for many useful comments on the manuscript. CM would like to thank Ruth Curry for support and updates for Hydrobase. AnneMarie Michael provided valuable editorial assistance in the preparation of the final text and figures. Finally, we would like to thank the two very helpful anonymous reviewers! Funding has been provided by the National Science Foundation through grants OCE 98-19066 and OCE 00-83268. This is WHOI Contribution 10574.

\section{References}

Andrié, C., J.-F. Ternon, M.-J. Messias, L. Memery, and B. Bourlès, Chlorofluoromethane distributions in the deep equatorial Atlantic during January-March 1993, Deep Sea Res., Part I, 45, 903-930, 1998.

Andrié, C., J.-F. Ternon, B. Bourlès, Y. Gouriou, and C. Oudot, Tracer distributions and deep circulation in the western tropical Atlantic during Cither 1 and Etambot cruises, 1993-1996, J. Geophys. Res., 104, 21,195-21,215, 1999.

Arhan, M., H. Mercier, B. Bourlès, and Y. Gouriou, Hydrographic sectons across the Atlantic at $7^{\circ} 30 \mathrm{~N}$ and $4^{\circ} 30 \mathrm{~S}$, Deep Sea Res., Part I, 45, 829$872,1998$.

Bowditch, N., American practical navigator: An epitome of navigation, vol. I, pp. 1313-1339, Def. Mapp. Agency Hydrogr./Topogr. Cent., Washington, D. C., 1984.

Bray, N. A., and N. P. Fofonoff, Available potential energy for MODE eddies, J. Phys. Oceanogr., 11, 30-46, 1981.

Cairns, J. L., and G. O. Williams, Internal wave observations from a midwater float, J. Geophys. Res., 81, 1943-1950, 1976.

Curry, R. G., Hydrobase: A database and tools for climatological analysis, Tech. Rep. WHOI-96-01, Woods Hole Oceanogr. Inst., Woods Hole, Oceanogr., 1996.

Fischer, J., M. Rhein, F. Schott, and L. Stramma, Deep water masses and transports in the Vema Fracture Zone, Deep Sea Res., Part I, 43, $1067-$ 1074, 1996.

Friedrichs, M. A. M., and M. M. Hall, Deep Circulation in the tropical North Atlanic, J. Mar. Res., 51, 697-736, 1993.

Garrett, C. J. R., and W. H. Munk, Space-time scales ofinternal waves: A progress report, J. Geophys. Res., 80, 291-297, 1975.

Gregg, M. C., Scaling turbulent dissipation in the thermocline, J. Geophys. Res., 94, 9686-9698, 1989.

Jenkins, W. J., P. A. Rona, and J. M. Edmond, Excess ${ }^{3} \mathrm{He}$ in the deep water over the Mid-Atlantic Ridge at $26^{\circ} \mathrm{N}$ : Evidence of hydrothermal activity, Earth Planet. Sci. Lett., 49, 39-44, 1980.

Johns, W. E., D. M. Fratantoni, and R. J. Zantopp, Deep western boundary current variability off northeastern Brazil, Deep Sea Res., Part I, 40, $293-310,1993$.

Lazier, J. R. N., The renewal of Labrador Sea Water, Deep Sea Res., 20, 341-353, 1973.

Lazier, J. R. N., Temperature and salinity changes in the deep Labrador sea, 1962-1986, Deep Sea Res., Part A, 35, 1247-1253, 1988.

Ledwell, J. R., E. T. Montgomery, K. L. Polzin, L. C. St. Laurent, R. W. Schmitt, and J. M. Toole, Evidence for enhanced mixing over rough topography in the abyssal ocean, Nature, 403, 179-182, 2000.

Lupton, J. E., Terrestrial inert gases: Isotope tracer studies and primordial components in the mantle, Ann. Rev. Earth Planet. Sci., 11, 371-414, 1983.

Lupton, J. E., Hydrothermal plumes: Near and far field, in Seafloor Hydrothermal Systems: Physical, Chemical, Biological, and Geological Interactions, Geophys. Monogr. Ser, vol. 91, edited by S. Humphris, R. Zierenberg, L. Mullineaux, and R. Thomson, pp. 317-346, AGU, Washington, D.C., 1985.

McCartney, M. S., Crossing of the equator by the Deep Western Boundary Current in the Western Atlantic Ocean, J. Phys. Oceanogr., 23, $1953-$ 1974, 1993.

McCartney, M. S., S. L. Bennett, and M. E. Woodgate-Jones, Eastward flow through the Mid-Atlantic Ridge at $11^{\circ} \mathrm{N}$ and its influence on the abyss of the eastern basin, J. Phys. Oceanogr., 21, 1089-1121, 1991.

McDougall, T., Parameterizing mixing in inverse models, Proceedings of Hawaiian Winter Workshop, 13 to 19 January 1991, pp. 355-386, School of Ocean and Earth Sci. and Technol., Univ. of Hawaii at Manoa, Honolulu, 1991.

Mercier, H., and K. G. Speer, Transport of bottom water in the Romanche Fracture Zone and the Chain Fracture Zone, J. Phys Oceanogr., 28, $779-$ 790, 1998. 
Molinari, R. L., R. A. Fine, and E. Johns, The Deep Western Boundary Current in the tropical North Atlantic Ocean, Deep Sea Res., Part A, 39 , 1967-1984, 1992.

Molinari, R. L., R. A. Fine, W. D. Wilson, R. G. Curry, J. Abell, and M. S. McCartney, The arrival of recently formed Labrador Sea Water in the Deep Western Boundary Current at $26.5^{\circ} \mathrm{N}$, Geophys. Res. Lett., 25, 2249-2252, 1998.

Osborn, T. R., Estimates of the local rate of vertical diffusion from dissipation measurements, J. Phys Oceanogr., 10, 83-89, 1980.

Pickart, R. S., M. A. Spall, and J. R. N. Lazier, Mid-depth ventilation in the western boundary current system of the subpolar gyre, Deep Sea Res. Part I, 44, 1025-1054, 1997.

Plähn, O., and M. Rhein, Measured and modeled CFC distribution of lower North Atlantic Deep Water in the Guiana Basin, J. Geophys. Res., 103, 2831-2847, 1998.

Polzin, K. L., Statistics of the Richardson number: Mixing models and fine structure, J. Phys. Oceanogr., 26, 1409-1425, 1996.

Polzin, K. L., J. M. Toole, and R. W. Schmitt, Finescale parameterizations of turbulent dissipation, J. Phys. Oceanogr., 25, 306-328, 1995.

Polzin, K. L., K. G. Speer, J. M. Toole, and R. W. Schmitt, Intense mixing of Antarctic Bottom Water in the equatorial Atlantic Ocean, Nature, 380 54-57, 1996.

Polzin, K. L., J. M. Toole, J. R. Ledwell, and R. W. Schmitt, Spatial variability of turbulent mixing in the abyssal ocean, Science, 276, $93-$ 96, 1997.

Polzin, K. L., E. Kunze, J. M. Toole, and R. W. Schmitt, The partition of finescale energy into internal waves and geostrophic motions, J. Phys. Oceanogr., in press, 2002.

Rhein, M., L. Stramma, and U. Send, The Atlantic Deep Western Boundary Current: Water masses and transports near the equator, J. Geophys. Res. 100, 2441-2457, 1995.

Rona, P. A., B. A. McGregor, P. R. Betzer, G. W. Bolger, and D. C. Krause,
Anomalous water temperatures over the Mid-Atlantic Ridge crest at $26^{\circ} \mathrm{N}$ latitude, Deep Sea Res., 22, 611-618, 1975.

Schmitt, R. W., J. M. Toole, R. L. Koehler, E. C. Mellinger, and K. W. Doherty, The development of a fine- and microstructure profiler, J. Atmos. Oceanic Technol., 5, 484-500, 1988.

Speer, K. G., The deep silica tongue in the North Atlantic, Deep Sea Res., 41, 925-936, 1993.

Speer, K. G., and M. S. McCartney, Tracing Lower North Atlantic Deep Water across the equator, J. Geophys. Res., 96, 20,443-20,448, 1991.

St. Laurent, L. C., J. M. Toole, and R. W. Schmitt, Buoyancy forcing by turbulence above rough topography in the abyssal Brazil Basin, J. Phys. Oceanogr., 31, 3476-3495, 2001.

Tarbell, S. A., A compilation of moored current meter data and associated oceanographic observations, vol. XXII, Polymode Array III Clusters A, B, and site moorings, 1977-1979, Tech. Rep. WHOI-80-40, 61 pp., Woods Hole Oceanogr. Inst., Woods Hole Oceanogr., Mass., 1980.

Toole, J. M., J. R. Ledwell, K. L. Polzin, R. W. Schmitt, E. T. Montgomery, L. St Laurent, and W. B. Owens, The Brazil Basin tracer release experiment, Int. WOCE Newsl., 28, 25-28, 1997.

Toole, J. M., K. L. Polzin, and R. W. Schmitt, A fine and microstructure section across the Continental Slope and Gulf Stream, Eos Trans. AGU, 80(49), Ocean Sci. Meet. Suppl., OS22H-02, 1999.

Vangriesheim, A., Antarctic Bottom Water flow through the Vema Fracture Zone, Oceanol. Acta, 3, 199-207, 1980.

C. Mauritzen, Norwegian Meteorological Institute, P.O. Box 43 Blindern, 0313 Oslo, Norway. (cecilie.mauritzen@met.no)

M. S. McCartney, R. C. Millard, K. L. Polzin, and D. E. West-Mack, Physical Oceanography Department, Woods Hole Oceanographic Institution, MS 21, Woods Hole, MA 02543, USA. (cmauritzen@whoi.edu) 